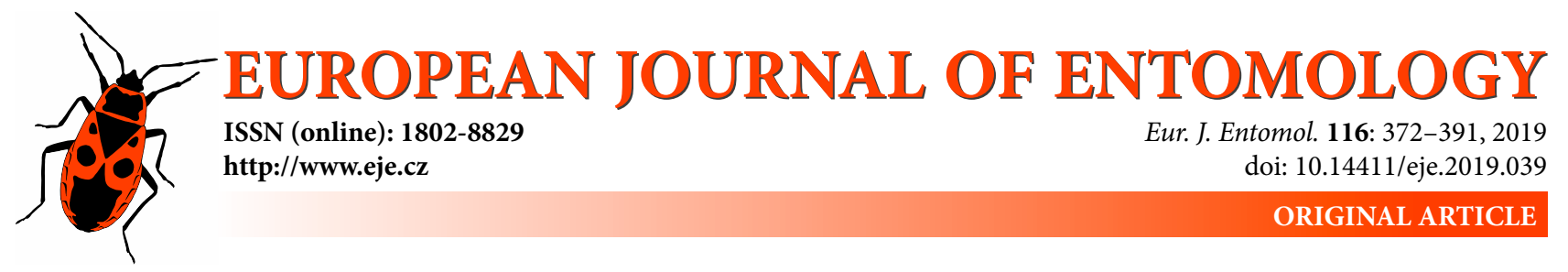

\title{
Identification and expression patterns of chemosensory proteins in the black-back prominent moth, Clostera restitura (Lepidoptera: Notodontidae)
}

\author{
Hui LI ${ }^{1,2}$, Tianzi GU ${ }^{1,2}$, Changyu CHEN ${ }^{1,2}$, Kairu HUANG ${ }^{1,2}$, Ruixu CHEN ${ }^{1,2}$ and Dejun HAO ${ }^{1,2, *}$ \\ ${ }^{1}$ Co-Innovation Center for the Sustainable Forestry in Southern China, Nanjing Forestry University, Nanjing, 210037 \\ Jiangsu, China; e-mails: 15720616317@163.com, tianzigu@gmail.com,1134614728@qq.com, 286412533@qq.com, \\ 1017385045@qq.com, djhao@ njfu.edu.cn \\ ${ }^{2}$ College of Forestry, Nanjing Forestry University, Nanjing, 210037 Jiangsu, China
}

Key words. Lepidoptera, Notodontidae, Clostera restitura, chemosensory proteins, expression pattern, phylogenetic analysis

\begin{abstract}
Insects have evolved highly specific and sensitive olfactory sensory systems to detect plant hosts and mates. Chemosensory proteins (CSPs) play an important role in this process, but in this respect there is limited information on Clostera restitura, one of the most destructive defoliators of poplars in China. In the present study, we first identified seven candidate CSPs in C. restitura. Sequence alignment and phylogenetic analysis showed that these candidate proteins possessed typical characteristics of the insect CSP family and were similar to those of other Lepidoptera. These genes were expressed in different developmental stages and tissues, and the levels of expression differed after mating. Some CresCSPs were more associated with development and others with mating. They may play an important role in host recognition, egg development and mating behaviour. Furthermore, the CSPs were ubiquitously detected in all tissues and most of them were highly expressed in antennae, especially female antennae. We suggest the CresCSPs may contribute to female oviposition site recognition. CresCSPs that are highly transcribed in wings and legs, may function in gustation. This study provides a better understanding of the molecular mechanisms of olfaction in $C$. restitura and environmentally friendly pest management strategy for controlling C. restitura.
\end{abstract}

\section{INTRODUCTION}

Clostera restitura Walker (Lepidoptera: Notodontidae) is one of the most destructive defoliators of poplar trees in China. This pest is widespread in southern China, especially in forest-rich provinces, such as Anhui, Jiangsu, Zhejiang, Shanghai, Fujian, Guangxi, Guang dong, Hunan and Hainan (Zhang, 1997; Liu et al., 2016; Fang et al., 2018; Xin et al., 2018). It also occurs widely in other Asian countries including India, Indonesia, Malaysia and Vietnam (Wu \& Fang, 2003; Schintlmeister, 2008). An outbreak of C. restitura usually causes severe economic damage in a surprisingly short period. More and more scientists are exploring the biological characteristics, behaviour and control strategies for C. restitura (Jing et al., 2007; Tang et al., 2008).

Insects have evolved highly specific and sensitive olfactory sensory systems to perceive chemical information from the environment and transform this information into electrical signals. This process is essential for insect feeding, courtship, defence and migration (Zwiebel \& Takken, 2004). Diverse kinds of proteins, odour binding proteins
(OBPs), chemosensory proteins (CSPs), odour receptors (ORs), odour degrading enzymes (ODEs), ion receptors (IRs) and sensory neuron membrane proteins (SNMPs), participate in chemical perception (Leal, 2013; Cao et al., 2014; Elfekih et al., 2016, Fleischer et al., 2018). Volatile chemical signals and other stimuli of lipophilic compounds cannot be directly transported to chemosensory receptors across hydrophilic lymph and must be bound by OBPs and CSPs (Yi et al., 2014a). Therefore, OBPs and CSPs, which are known as carrier proteins, play key roles in insect olfaction (Dani et al., 2011).

CSPs and well-studied OBPs, are low-molecular-mass and soluble proteins used in insect chemoreception (Pelosi et al., 2006). CSPs are characterized by four cysteine residues $\left(\mathrm{C}_{1}-\mathrm{X}_{6-8}-\mathrm{C}_{2}-\mathrm{X}_{16-21}-\mathrm{C}_{3}-\mathrm{X}_{2}-\mathrm{C}_{4}\right)$ that form two disulfide bridges (Tomaselli et al., 2006). Similar to OBPs, the rigid hydrophobic pocket in CSPs can capture and transport external chemical cues to receptors. CSPs were first discovered in the antennae of Drosophila melanogaster (Mckenna et al., 1994). Further studies revealed that CSPs were expressed not only in antennae but also in other insect

\footnotetext{
* Corresponding author; e-mail: djhao@njfu.edu.cn
} 
tissues, including legs (Picimbon et al., 2001), pheromone glands (Dani et al., 2011), wings (Zhu et al., 2015), proboscises (Liu et al., 2014), labial palps and maxillae (Angeli et al., 1999), which differs from OBPs.

The multi-tissue expression pattern of CSPs indicate they may also have other functions, apart from chemo sensation (Tegoni et al., 2004). In fact, with the development of genome and transcriptome sequencing, recent studies have demonstrated that CSPs do contribute to other physiological processes (Zhu et al., 2015; Kang, 2016; Zhang et al., 2017; Ting et al., 2018; Zeng et al., 2018). As carrier proteins, CSPs bind with small molecules, for instance nutrients, toxic compounds, hormones and semiochemicals, (Pelosi et al., 2017). Most CSPs identified in Bombyx mori (Dani et al., 2011; Qiao et al., 2013), Plutella xylostella (Liu et al., 2010) and Sesamia inferens (Zhang et al., 2013) are widely expressed not only in antenna but also the female sex pheromone gland, which indicates a role in insect mating. In addition, CSP6 of Helicoverpa armigera is highly transcribed in sensory organs and pheromone glands, and has high binding affinity for pheromone components, which reveals that HarmCSP6 is probably involved in transporting female sex pheromones in $H$. armigera $(\mathrm{Li}$ et al., 2015). A decrease in CSPs is associated with reduced survival and fecundity in females of Spodoptera exigua, which demonstrates that female survival and reproduction is closely associated with CSPs transcription (Gong et al., 2012). Xin et al. (2017) reports that the mid gut expressed CSPs in Spodoptera litura may be responsible for its ability to adapt to different ecosystems. Populations of insecticide-resistant Diatraea saccharalis have a higher CSPs transcription than susceptible populations, which indicates that CSPs participate in this insect's immune response. A similar phenomenon is reported in Tribolium castaneum (Guo et al., 2012; Gao et al., 2018). Moreover, CSPs are essential for the development of the embryonic integument of Apis mellifera, behavioural phase change in migratory locust and insect tissue regeneration (Pelosi et al., 2006; Maleszka et al., 2007; Guo et al., 2011). Notably, RNAi reduction in NlugCSP8 transcript abundance causes a decrease in the behavioural response to particular attractants, which is likely to result in more effective and eco-friendly control strategies for the brown plant hopper (Muhammad et al., 2018).

This laboratory previously constructed a cDNA library for $C$. restitura and characterized the expression profiles of OBPs. It is likely that OBPs play a key role in foraging, seeking mates and host recognition in C. restitura $(\mathrm{Gu}$ et al., 2019). In addition, we cloned the full-length of the cDNA encoding CresCSP3 and analyzed its tissue specific expression pattern. The CresCSP3 transcripts detected in heads, antennae, wings and legs indicate they may contribute to insect development, mating behaviour and host location (Li et al., 2018). In this study, sequence cloning and analysis of the patterns of expression of CresCSPs are used to determine the physiological roles of 7 other CSPs in $C$. restitura, which will help in the development of eco- friendly techniques to be used in the control $C$. restitura in the future.

\section{MATERIALS AND METHODS}

\section{Insect rearing and sample collection}

Clostera restitura eggs were collected from the leaves of 7-year-old Populus euramericana cv. I-72 trees in an agricultural afforestation area, Pukou District, Nanjing $\left(32^{\circ} 180^{\prime} \mathrm{N}, 118^{\circ} 28^{\prime} \mathrm{E}\right)$, Jiangsu Province, China and kept in an incubator $\left(26 \pm 0.5^{\circ} \mathrm{C}, 70\right.$ $\pm 5 \%$ relative humidity, $16 \mathrm{~L}: 8 \mathrm{D}$ photoperiod) at the Laboratory of Entomology at Nanjing Forestry University. On hatching, larvae were transferred to $15-\mathrm{cm}$-diameter sterilized Petri dishes and reared on fresh leaves of Populus deltoides. Pupae were placed in individual tubes. On emergence the adults were put into plastic boxes $(15 \times 10 \times 10 \mathrm{~cm})$ and fed ad libitum a $10 \%$ honey solution. The second generation eggs, larvae, pupae and adults were used in the experiments.

For the analysis of the pattern of expression, eggs $(\mathrm{N}=30), 1^{\text {st }}$ to $5^{\text {th }}$ instar larvae $(\mathrm{N}=3)$, pupae $(\mathrm{N}=3)$, antennae of $1-6$ day old virgin males and females $(\mathrm{N}=30)$ and antennae of mated and virgin adults $(\mathrm{N}=30)$ were collected. The antennae, heads (without antennae, $\mathrm{N}=3)$, legs $(\mathrm{N}=30)$ and wings $(\mathrm{N}=6)$ were dissected from newly emerged male and female adults. All these samples were immediately frozen in liquid nitrogen and stored at $-80^{\circ} \mathrm{C}$.

\section{RNA extraction, cloning and sequencing}

Total RNA was isolated using TRIzol Reagent (Ambion, State of Texas, USA) following the manufacturer's instructions, before checking the quantity of RNA. First-strand cDNA for RT-PCR and RT-qPCR were synthesized from $1 \mu \mathrm{g}$ total RNA using 1st Strand cDNA Synthesis Kit (TaKaRa, Dalian, China). Seven pairs of specific oligonucleotide primers (Table S1) were designed based on the transcriptome database for $C$. restitura ( $\mathrm{Gu}$ et al., 2019) and used to amplify the complete open reading frames (ORFs). We performed PCRs to amplify the specific genes, following the manufacturer's protocol (Zoman, Beijing, China). Amplification products were purified using a DNA purification system (Tiangen, Beijing, China) and cloned into a pEasy-T1 cloning vector (TransGen Biotech, Beijing, China). Seven randomly selected positive clones per construct were sequenced.

\section{Sequences and phylogenetic analyses}

The ORFs of the putative chemosensory genes were identified using ORF Finder (http://www.ncbi.nlm.nih.gov/gorf/gorf.html) (Min et al., 2005). Similarity searches were performed using NCBI-BLAST (http://blast.ncbi.nlm.nih.gov/). Sequence alignments were performed using DNAMAN version 6.0. Signal peptides were identified using SignalP 4.0 (http://www.cbs.dtu.dk/services/SignalP/) (Petersen et al., 2011). The molecular weights and isoelectric points of mature proteins were calculated using the ExPASy server program (http://www.expasy.ch/cgi-bin/pi_tool).

Phylogenetic trees were constructed based on the cDNA sequences of CSPs from $C$. restitura and CSPs in other Lepidoptera in the UniGene database at NCBI. Maximum-likelihood phylogenetic trees were constructed using MEGA 6 and bootstrapping of 1,000 replicates (Tamura et al., 2011).

\section{Real-time quantitative PCR}

To determine the potential functions of the CSPs, we measured the relative levels of expression of these genes in the different developmental stages, virgin and mated individuals and different tissues using qPCR. We performed RT-qPCR with the previously mentioned cDNA templates. Reactions of each sample of the three biological replicates were run in triplicate. The qRT-PCR primers (Table S1) were designed online (https://www.genscript. 
com/tools/real-time-pcr-tagman-primer-design-tool). The RPS13 gene was used as a reference gene (Gu et al., 2019). qRT-PCRs were performed in an Applied Biosystem 7500 System (USA) using SYBR Premix Ex Taq II (TaKaRa, Dalian, China), according to the manufacturer's protocol. The cycling conditions were (1) $95^{\circ}, 30 \mathrm{~s}$; (2) $95^{\circ}, 5 \mathrm{~s}$; (3) $60^{\circ}, 34 \mathrm{~s}$; (4) go to (2) for 40 cycles, and this procedure was followed by an analysis of melting curves ranging from 60 to $95^{\circ} \mathrm{C}$ to verify the presence of a single discrete peak for each reaction product. The cDNA templates in 10-fold dilution series were used to construct a relative standard curve to determine the PCR efficiency. In all experiments, all primers achieved amplification efficiencies of $95-100 \%$ (Table S1). The results of qRT-PCRs were analyzed using the $2^{-\Delta \Delta \mathrm{Ct}}$ method (Livak \& Schmittgen, 2001).

\section{Statistical analysis}

All data was processed using SPSS Statistics V20.0 (IBM). A one-way analysis of variance (ANOVA) with least significant difference (LSD) was used to analyze the patterns in the expression of genes in the various samples.

\section{RESULTS}

\section{Identification of CSP genes in C. restitura}

Based on the unigenes of the CSPs annotated in the $C$. restitura antennal transcriptome database ( $\mathrm{Gu}$ et al., 2019), we used PCR to clone seven CSP genes from antennae of $C$. restitura, and the sequences of these genes were deposited in GenBank with accession numbers presented in Table S2. All of these CSPs had full-length ORFs with four conserved cysteines in the same corresponding positions according to multiple alignments of amino acid sequences of the seven CresCSPs (Fig. 1). The ORFs of CresCSP1-7 ranged from 321 to $387 \mathrm{bp}$ in length and the predicted molecular weight varied from 11.81 to $14.73 \mathrm{kDa}$. In addition, they were all predicted to have signal peptides of 16 to 18 amino acids in length and isoelectric points from 5.35 to 8.58 (Table S2). The results of a BLASTX search showed that CresCSP1 to CresCSP7 were very similar to the CSPs in other Lepidoptera $(>64 \%)$, especially the CSPs in $S$. litura and B. mori, whereas CresCSP8 was not similar to the CSPs of these organisms (39\%).

\section{Phylogenetic analyses of the CSP genes in $C$. restitura}

A phylogenetic tree was constructed based on the cDNA sequences of CSPs from C. restitura and other Lepidoptera, including B. mori, Eogystia hippophaecolus, Grapholita

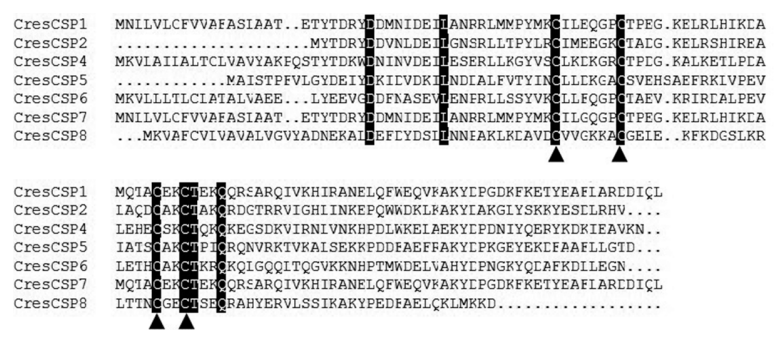

Fig. 1. Alignment of mature CresCSP01, CresCSP02, CresCSP04, CresCSP05, CresCSP06, CresCSP07 and CresCSP08 from C. restitura. Conserved amino acids in all CSPs are shown with a black background. Positions of the four conserved cysteine residues are indicated by triangles.

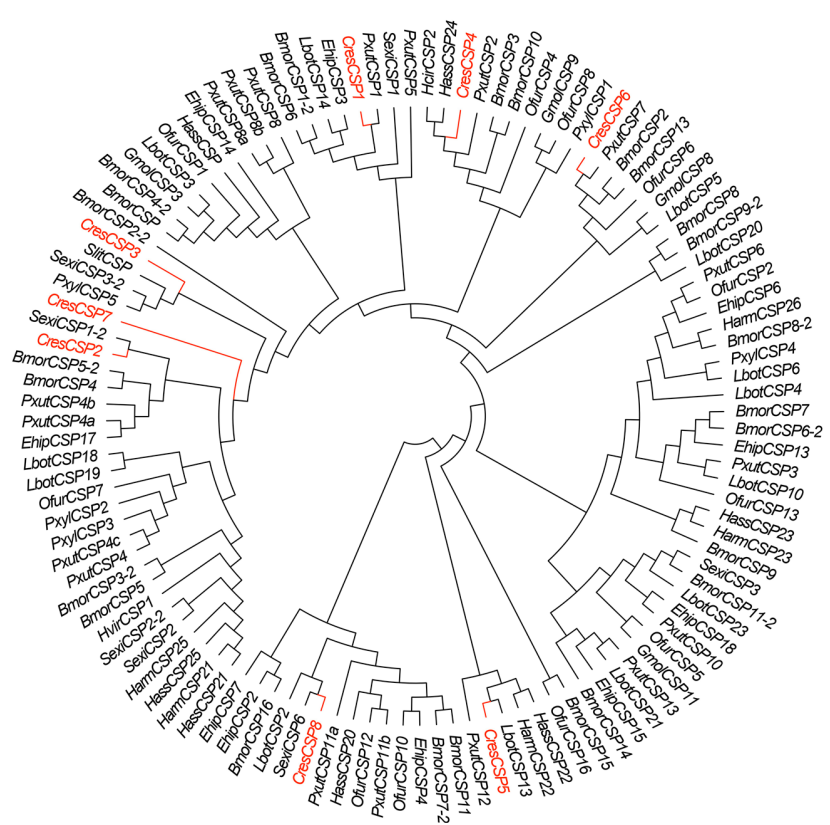

Fig. 2. Phylogenetic analysis of cDNA sequences of CresCSPs and those of other Lepidoptera using the maximum likelihood method with 1,000 bootstrap replications. The sequences used in the construction of this phylogenetic tree are listed in Table S3.

molesta, H. armigera, Heliothis virescens, Lobesia botrana, Ostrinia furnacalis, Papilio xuthus, Plutella xylostella, S. exigua and S. litura (Fig. 2). The Maximum-Likelihood (ML) tree indicated that these seven Cres CSPs occur on different branches. CresCSP1 and CresCSP6 were clustered with CSPs from P. xuthus (PxutCSP1 and PxutCSP7) in one subbranch, while CresCSP2 and CresCSP8 occurred on separate branches along with SexiCSP1-2 and SexiCSP6, respectively. CresCSP5 was very similar to LbotCSP13, whereas CresCSP4 was on a branch with CSPs from Noctuidae (Fig. 2).

\section{Patterns of expression of CSP in C. restitura}

Stage-specific expression of CSPs in C. restitura

All seven CresCSPs were expressed throughout the life cycle of C. restitura (Figs 3-4). However, the expression patterns of CSPs in $C$. restitura differed in different stages. CresCSP7 was expressed in eggs at relatively high levels. In the first instar, CresCSP4, CresCSP5 and CresCSP6 were transcipted significantly. mRNAs of CresCSP1 and CresCSP2 were especially dominant in the second and third instar, while that of CresCSP8 was strongly detected in the fourth and last instar.

The expression patterns of CSP genes after adult emergence were shown in Fig. 4. CresCSP1 and CresCSP8 were expressed mainly in 3-day-old females and males. CresCSP2 showed high levels of expression in 4-day-old males, while CresCSP4 and CresCSP5 were abundant in 4-day-old females. In addition, in 1-day-old $C$. restitura females there were many transcriptomes of CresCSP6, CresCSP7 and CresCSP8. 

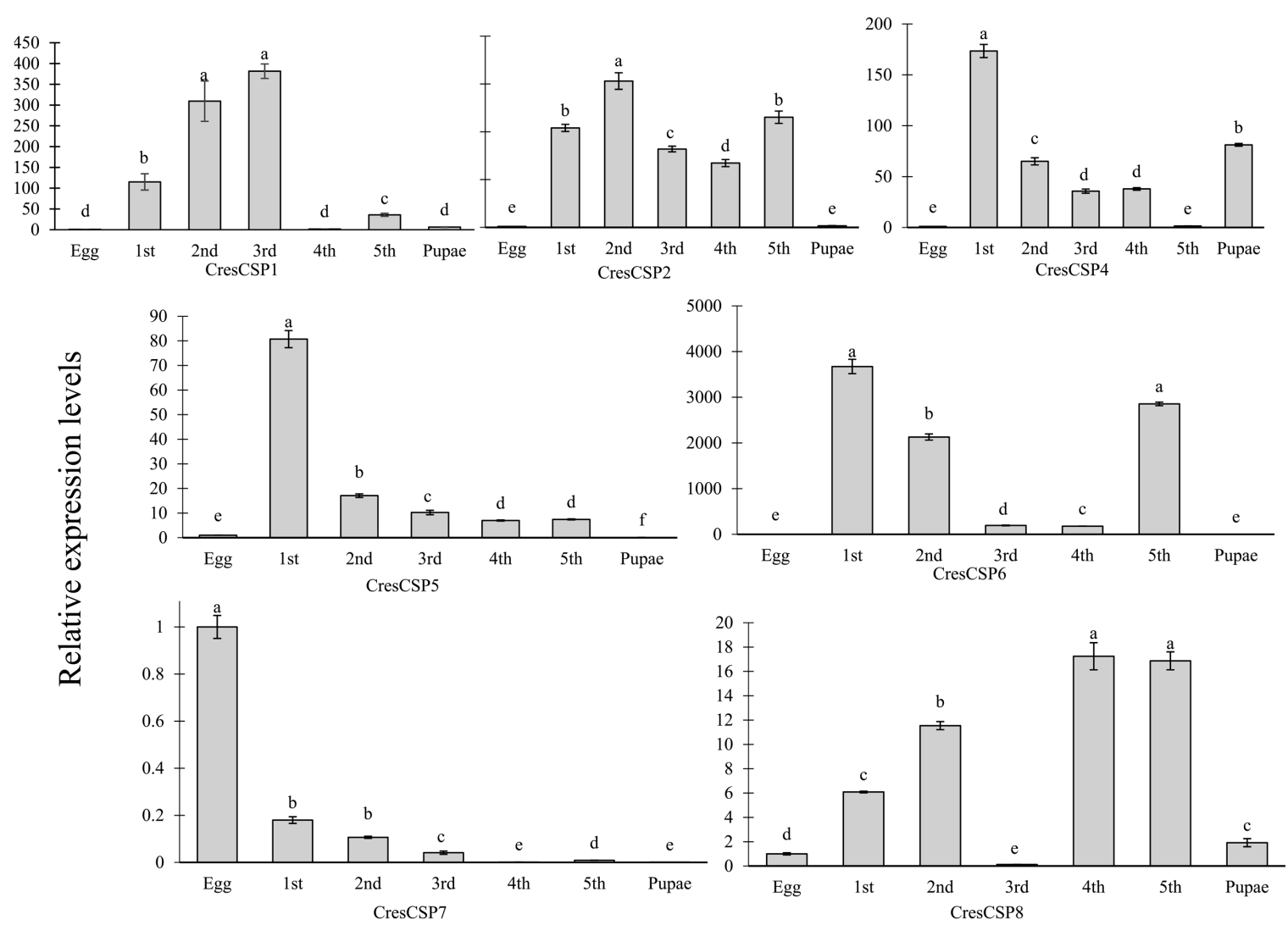

Fig. 3. Relative levels of expression of CresCSPs in eggs, larvae of different instars and pupae determined using qPCR. Data presented are the means of three replicates. Different lower case letters indicate significant differences $(P<0.05)$.
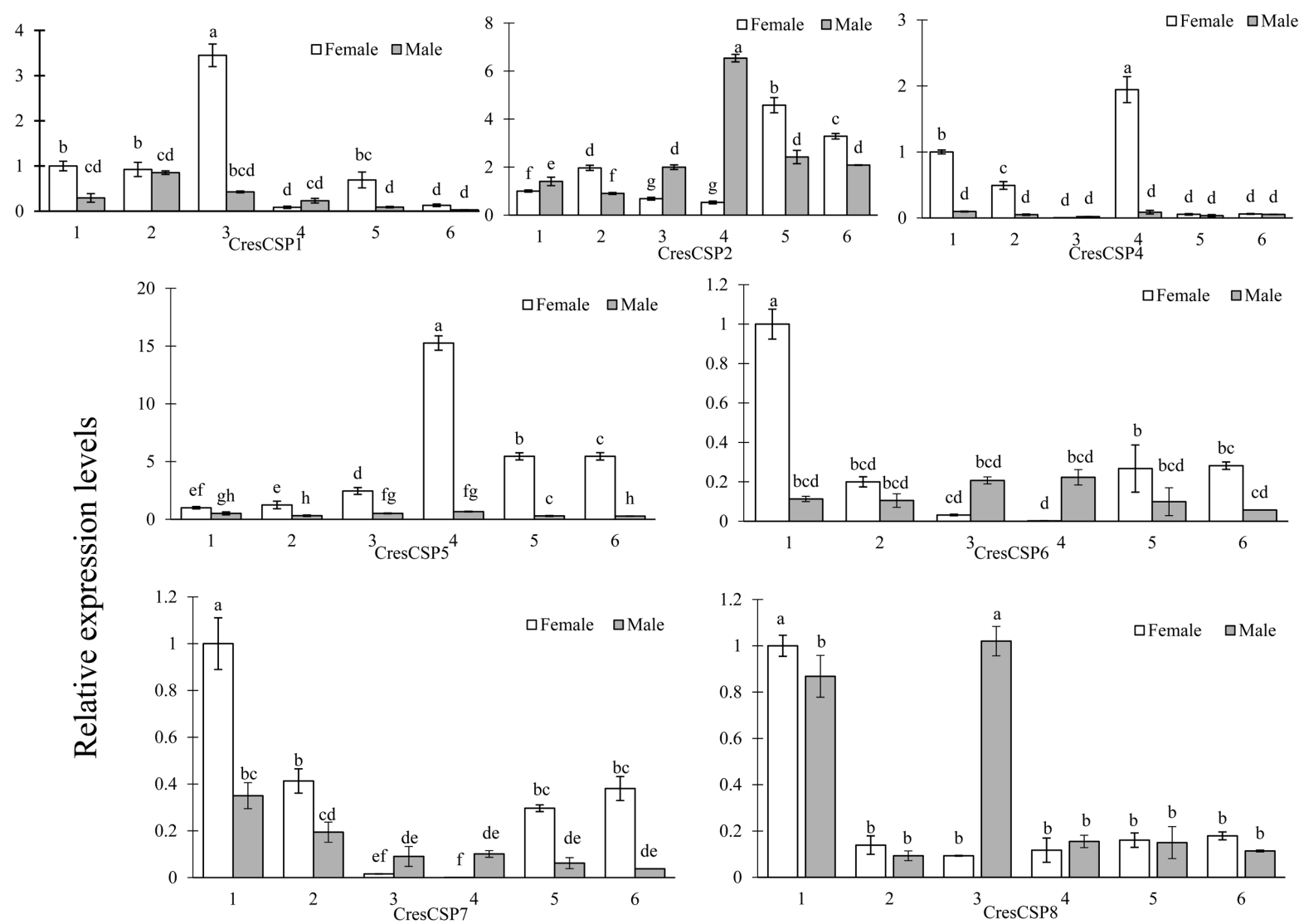

Fig. 4. Relative levels of expression of CresCSPs in 1 to 6-day-old female and male adults determined using qPCR. 1 - 1-day-old, 2 2-day-old, 3-3-day-old, 4-4-day-old, 5-5-day-old and 6-6-day-old. Data presented are the means of three replicates. Different lower case letters indicate significant differences $(P<0.05)$. 

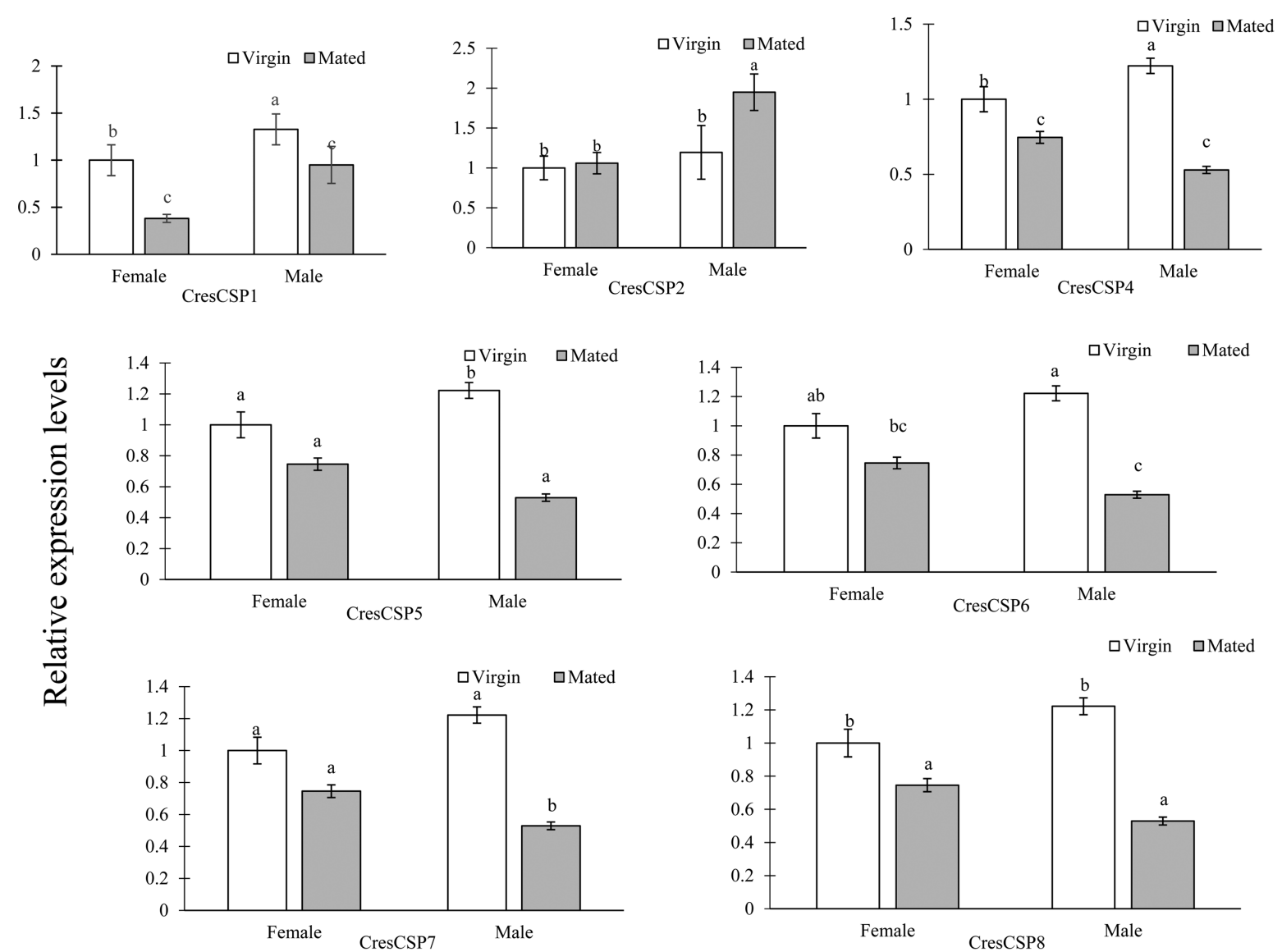

Fig. 5. Relative levels of expression of CresCSPs in virgin and mated adults determined using qPCR. Data presented are the means of three replicates. Different lower case letters indicate significant differences $(P<0.05)$.

\section{Mating-specific expression of CSPs in C. restitura}

The expression levels of CSP genes associated with mating status were shown in Fig. 5. Adult males had less mRNA of CresCSP1, CresCSP4, CresCSP6 and CresCSP7 after mating, but there were many transcripts of CresCSP2, CresCSP5 and CresCSP8 in mated males. There was an increase in the expression raised of CresCSP8 in mated females of $C$. restitura and decrease in the expression of CresCSP1 and CresCSP4 after mating.

\section{Tissue-specific expression of CSPs in C. restitura}

The qRT-PCR results revealed that seven genes in $C$. restitura were expressed at different levels in a wide range of tissues (Fig. 6). All seven CresCSPs, however, were mainly detected in antennae, with higher transcription levels of almost all the CresCSPs except for CresCSP2 in female antennae than in male antennae. We also recorded an enriched level of transcripts of CresCSP1, CresCSP7 and CresCSP8 in the wings of $C$. restitura and a recordable amount of those of CresCSP1, CresCSP2 and CresCSP8 in the legs.

\section{DISCUSSION}

We have compiled a library of the cDNA and thirteen CSPs in the antennae of $C$. restitura in order to identify the olfactory-related genes expressed in its antennae (Gu et al., 2019). Currently, eight CSPs with high levels of tran- scription among the thirteen CresCSPs from the antennae of $C$. restitura were cloned, which is fewer than that reported in other Lepidoptera. The number of CSPs varied among Lepidoptera. According to previous studies, there were twenty candidate CSPs in B. mori (Gong et al., 2007), 14 in third instar larvae of E. obliqua (Sun et al., 2017) and 24 in H. armigera (Li et al., 2015). These results indicated that the number of CSPs genes varied in insects and was associated with different ligands that enabled them to adapt to changing environmental conditions. BLASTX results indicated that CresCSPs were very similar to the CSPs in other Lepidoptera, e.g., CSPs in S. litura and B. mori, which implied that CSPs in insects were highly conserved. In addition, the bioinformatics analysis showed that CresCSPs have the same signature as other CSPs, low molecular weight, an $\mathrm{N}$-terminal signal peptide sequence and four conserved cysteine residues, which supported the hypothesis that CSPs were highly conserved (Wanner et al., 2014).

The phylogenetic analysis showed that different CresCSPs had a distant genetic relationship. Similar results were reported for many Lepidoptera (Liu et al., 2010; Li et al., 2015; Zhu et al., 2015; Sun et al., 2017). The diversification of CSP-encoding genes in C. restitura might be correlated with the various functions of CresCSPs. Similarly, Gong et al. (2015) reported six of seven CsupCSP genes were in each branch with Papilionidae CSPs. We also found that 

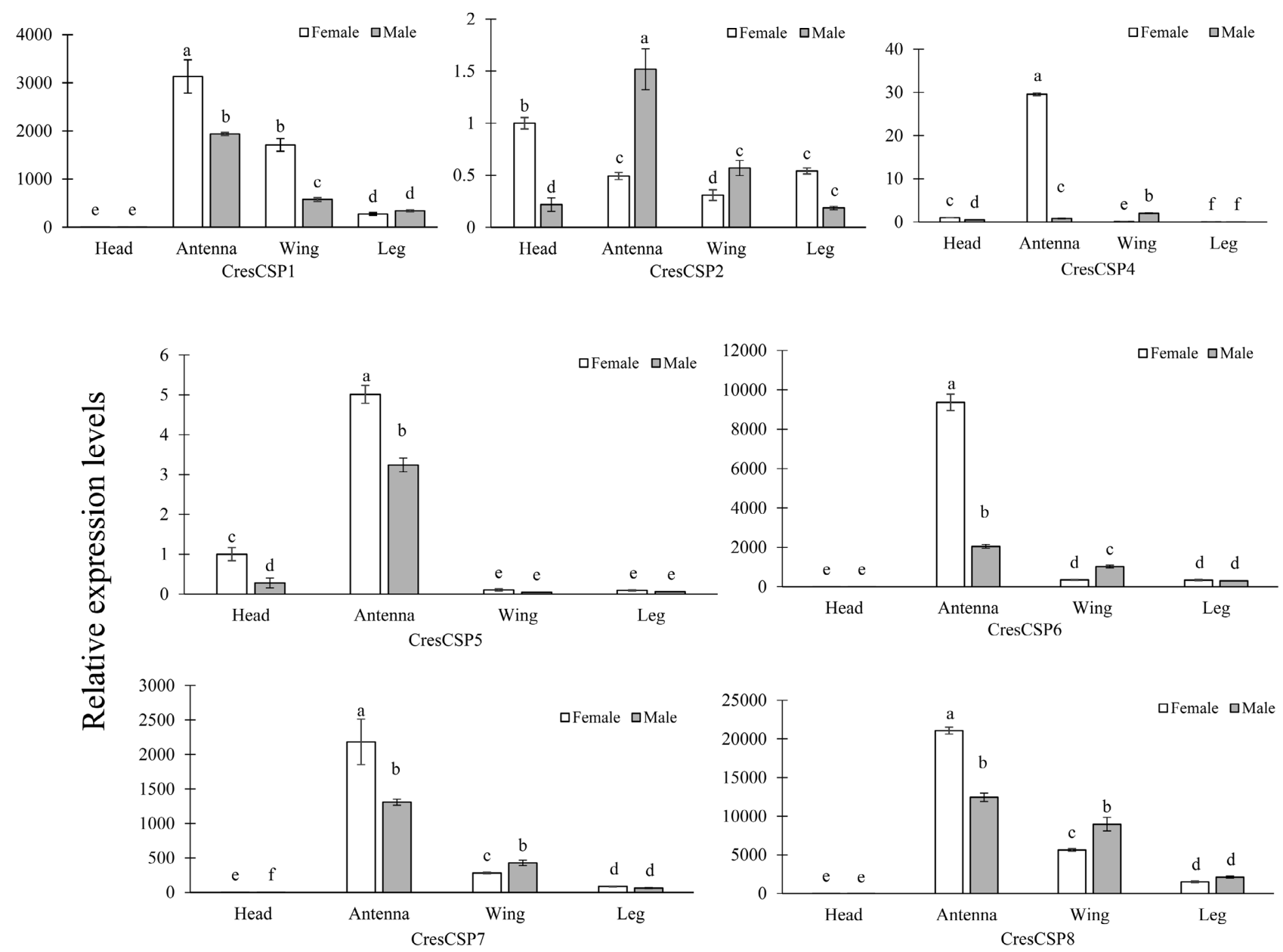

Fig. 6. Relative levels of expression of CresCSPs in head (without antennae), antennae, wings and legs determined using qPCR. Data presented are the means of three replicates. Different lower case letters indicate significant differences $(P<0.05)$.

six of eight CresCSPs form a branch with CSPs from other Lepidoptera, especially the Noctuidae, which suggests that CresCSP genes may have evolved similarly to that of CSP genes in other moths. Although these species belong to different families, the CSPs in these insects were conserved, indicating that the diversification of CSPs within a family might by duplication (Zhu et al., 2015).

Investigations of the expression patterns of chemosensory protein genes in the different development stages, sexes, individuals of different mating status and tissues in C. restitura, might provide new insights into the functions of CSPs. We found transcripts of all CresCSPs in all the developmental stages, but the levels of expression differed in each stage. For example, CresCSP7 was recorded mainly in eggs and CresCSP4, CresCSP5 and CresCSP6 mainly in 1st-larvae. Therefore, we speculated that CresCSP7 might be involved in the development of the eggs of $C$. restitura and CresCSP4, CresCSP5 and CresCSP6 in the searching for food after hatching. Our results were consistent with the study of CSP5 in Apis mellifera using RNAi, which shows that CSPs were involved in embryonic development (Maleszka et al., 2007). In addition, we found that CresCSP1, CresCSP2 and CresCSP8 were abundant in 2nd to 4th instar larvae. Under natural conditions, 2nd instar larvae of C. restitura rapidly consumed leaves and moved from de- foliated trees to other trees in the vicinity in search of food (Sangha et al., 2005). These CresCSPs might contribute to perception by larvae of polar volatiles. An increasing number of studies indicated that insect CSPs were responsive to host plant volatiles (Liu et al., 2010; Hua et al., 2013; Yi et al., 2014b), thus, the CresCSPs might be responsible for the perception by larvae of polar volatiles.

After emergence, $C$. restitura males and females mated with each other when they were 3 to 4 days old (Sangha et al., 2005). Interestingly, most of CresCSPs, such as CresCSP1, CresCSP2, CresCSP4, CresCSP5 and CresCSP8 were mainly expressed in 3 to 4-day-old adults and, therefore, might be associated with mating behavior, in particular the secretion of sex-pheromone by females of C. restitura and their location by males. Many studies revealed that CSPs had a close connection with insect mating and egg-laying (Gong et al., 2012, 2015; Ju et al., 2014). Ligand-binding assays of CSPs in Plutella xylostella and Sesamia inferens reported higher binding to non-volatile oviposition deterrents and pheromone components, which supported the above suggestion (Liu et al., 2010; Zhang et al., 2014). Our results accorded with these studies and confirm the participation of CresCSPs in mating behaviour. Sower et al. (1973) certified that insect males and females produced sex-pheromones in order to attract each 
other and for release before mating (Sower et al., 1973). Recently, many studies suggested high levels of transcription of CSPs in the sex pheromone gland of females (Dani et al., 2011; Gu et al., 2013; Zhang et al., 2013). In this research, the low expression of CresCSP1 and CresCSP4 in mated adults indicated that CSP proteins could store pheromone components before release. The abundance of transcripts of CresCSP2, CresCSP5 and CresCSP8 in mated males reflected their role in mate seeking behaviour. It was worth noting that these three CresCSPs were more associated with mating behaviour than with ageing. Females of $C$. restitura normally couldn't automatically oviposit at spawning sites, but first examined them using their tarsal sensillae (Thompson, 1988; Singh \& Sangha, 2012). The post mating up-regulation of the expression of CresCSP8 in females of $C$. restitura revealed that this gene might be involved in the search for oviposition sites.

Analysis of the patterns in the expression of chemosensory genes in insects might contribute to predicting their functions. Like OBPs, CSPs were mainly expressed in insect antennae. In our study, most CresCSPs were highly expressed in the antennae, especially in female antennae (except for CresCSP2), which manifested that CresCSPs might participate in chemosensory processes. These results were similar to patterns of expression of CSP18 in Athetis lepigone and CSP14 and CSP15 in H. armigera (Li et al., 2015; Zhang et al., 2017). Our previous studies discovered a high enrichment of two pheromone binding proteins PBPs (CresPBP1 and -PBP3) and three OBPs (CresOBP9, -10, and -16 ) in male antennae ( $\mathrm{Gu}$ et al., 2019). We speculated that OBPs might contribute to recognition of pheromone molecules, whereas most CresCSPs play an important role in the recognition of spawning sites or binding host volatiles in females of $C$. restitura.

CresCSPs were widely distributed in chemosensory tissues in the head, antennae, wings and legs, which suggested they might be associated with physiological processes other than olfaction (Yang et al., 2014). Some CresCSPs (CresCSP1, CresCSP7 and CresCSP8) were highly transcribed in wings, which revealed they might be associated there with gustatory functions (Xu et al., 2009). In addition, there were high expressions of CSPs in the legs of many insects, such as, S. litura, S. exiguas and Cyrtorhinus lividipennis (Zhang et al., 2012; Zhu et al., 2015; Wang et al., 2017). A certain amount of CresCSP1, CresCSP2 and CresCSP8 was also recorded in the legs of $C$. restitu$r a$, which based on the conclusions of Kitabayashi et al. (1998), might indicate they were involved in regeneration or help in the regeneration of their legs. Some reports indicated the CresCSPs in the legs might have a gustatory function. To some extent, the expression of CresCSPs in legs could be associated with the creeping behavior occasionally related to feeding in adult $C$. restitura. This chemosensory function remained to be verified.

In this study, seven CresCSPs were identified in the antennae of $C$. restitura. Different levels of expression of the CresCSPs and a phylogenetic analysis indicated that these genes had particular functions. These genes were ex- pressed in all the developmental stages and tissues tested, and the levels of expression changed after mating. It was possible they had an important role in olfaction and other physiological processes. We aim to further the understanding of the biological functions of these CSP genes in the future by ligand-binding, RNAi and CRISPR/Cas9 experiments. This study provides valuable information on the molecular mechanisms of olfaction in C. restitura and a possible novel way of controlling $C$. restitura and other Lepidoptera pest.

ACKNOWLEDGEMENTS. This work was supported by the Natural Science Foundation of China (31170606, 31470650), Postgraduate Research \& Practice Innovation Program of Jiangsu Province (KYCX19-1083), the Natural Science Foundation of Jiangsu Province (BK20131421) and the Priority Academic Program Development (PAPD) of Jiangsu Province.

\section{REFERENCES}

Angeli S., Ceron F., Scaloni A., Monti M., Monteforti G., Minnocci A., Petacchi R. \& Pelosi P. 1999: Purification, structural characterization, cloning and immunocytochemical localization of chemoreception proteins from Schistocerca gregaria. - Eur. J. Biochem. 262: 745-754.

Cao D.P., Liu Y., Wei J.J., Liao X.Y., Walker W.B., Li J.H. \& WANG G.R. 2014: Identification of candidate olfactory genes in chilo suppressalis by antennal transcriptome analysis. - Int. J. Biol. Sci. 10: 846-860.

Dani F.R., Michelucci E., Francese S., Mastrobuoni G., Cappellozza S., Marca G.L., Niccolini A., Felicioli A., Moneti G. \& Pelosi P. 2011: Odorant-binding proteins and chemosensory proteins in pheromone detection and release in the silkmoth Bombyx mori. — Chem. Senses 36: 335-344.

Elfekin S., Chen C.Y., Hu J.C., Belcaid M. \& Haymer D. 2016 : Identification and preliminary characterization of chemosensory perception-associated proteins in the melon fly Bactrocera cucurbitae using RNA-seq. - Sci. Rep. 6: 19112, 10 pp.

Fang L.C., Liu H.L., Wei S.Y., Keefover-Ring K. \& Yin T.M. 2018: High-density genetic map of populus deltoides constructed by using specific length amplified fragment sequencing. - Tree Genet. Genom. 14: 79, 10 pp.

Fleischer J., Pregitzer P., Breer H. \& Krieger J. 2018: Access to the odor world: olfactory receptors and their role for signal transduction in insects. - Cell. Mol. Life Sci. 75: 485-508.

Gao S.S., Xiong W.F., Wei L., Liu J.J., Liu X., Xie J., Song X. \& BI J.X. 2018: Transcriptome profiling analysis reveals the role of latrophilin in controlling development, reproduction and insecticide susceptibility in Tribolium castaneum. - Genetica 146: 287-302.

Gong D.P., Zhang H.J., Zhao P., Lin Y., Xia Q.Y. \& Xiang Z.H. 2007: Identification and expression pattern of the chemosensory protein gene family in the silkworm, Bombyx mori. - Insect Biochem. Mol. Biol. 37: 266-277.

Gong L., Luo Q., Rizwan-Ul-HaQ M. \& Hu M.Y. 2012: Cloning and characterization of three chemosensory proteins from Spodoptera exigua and effects of gene silencing on female survival and reproduction. — Bull. Entomol. Res. 102: 600-609.

Gong Z.J., Liu S., Jiang Y.D., Zhou W.W., Liang Q.M., Cheng J., Zhang C.X., Zhu Z.R. \& GurR G.M. 2015: Construction and analysis of antennal cDNA library from rice striped stem borer, Chilo suppressalis (Walker) (Lepidoptera: Pyralidae), and expression profiles of putative odorant-binding protein and chemosensory protein genes. - Arch. Insect Biochem. Physiol. 89: $35-53$. 
Gu T.Z., Huang K.R., Tian S., Li H., Chen C. \& Hao D.J. 2019: Antennal transcriptome analysis and expression profiles of odorant binding proteins in Clostera restitura. - Comp. Biochem. Physiol. (D) 29: 211-220.

Guo W., Wang X., Ma Z., Xue L., Han J., Yu D. \& Kang L. 2011: CSP and Takeout genes modulate the switch between attraction and repulsion during behavioral phase change in the migratory locust. - PLoS Genet. 7(2), e1001291, 13 pp.

Guo Z., Cheng Z.Y., Huang F., Luttrell R. \& Leonard R. 2012: Microarray analysis of global gene regulation in the Cryl Abresistant and Cry1 Ab-susceptible strains of Diatraea saccharalis. - Pest Manag. Sci. 68: 718-730.

Hua J.F., Zhang S., Cui J.J., Wang D.J., Wang C.Y., Luo J.Y., LV L.M. \& MA Y. 2013: Functional characterizations of one odorant binding protein and three chemosensory proteins from Apolygus lucorum (Meyer-Dur) (Hemiptera: Miridae) legs. J. Insect Physiol. 59: 690-696.

JING T.Z., WANG Z.Y. \& QI F.H. 2007: Molecular characterization of diapause hormone and pheromone biosynthesis activating neuropeptide from the black-back prominent moth, Clostera anastomosis (Lepidoptera, Notodontidae). - Insect Biochem. Mol. Biol. 37: 1262-1271.

Ju Q., Li X., Jiang X.J., Qu M.J., Guo X.Q., Han Z.J. \& Li F. 2015: Transcriptome and tissue-specific expression analysis of $\mathrm{OBP}$ and CSP genes in the dark black chafer. - Arch. Insect Biochem. Physiol. 87: 177-200.

KANG K. 2016: Identification and Expression of Olfactory Genes in Hyphantria cunea (Drury). MSc Thesis, Anhui Agricultural University, pp. 25-57.

Kitabayashi A.N., Arai T., Kubo T. \& Natori S. 1998: Molecular cloning of cDNA for $\mathrm{p} 10$, a novel protein that increases in the regenerating legs of Periplaneta americana (American cockroach). - Insect Biochem. Mol. Biol. 28: 785-790.

LEAL W.S. 2013: Odorant reception in insects: roles of receptors, binding proteins, and degrading enzymes. - Annu. Rev. Entomol. 58: 373-391.

Li Z.Q., Zhang S., Luo J.Y., Zhu J., CuI J.J. \& Dong S.L. 2015: Expression analysis and binding assays in the chemosensory protein gene family indicate multiple roles in Helicoverpa armigera. - J. Chem. Ecol. 41: 473-485.

Li H., Gu T.Z., Chen C.Y., Huang K.R., Tian S., Zhao X.D. \& Hao D.J. 2018: cDNA cloning, sequence analysis and expression profile of a chemosensory protein from the Clostera restitura (Lepidoptera: Notodontidae). - Sci. Silv. Sin. 54(4): $67-75$.

Liu X., Luo Q., Zhong G., Rizwanulhaq M. \& Hu M. 2010: Molecular characterization and expression pattern of four chemosensory proteins from diamondback moth, Plutella xylostella (Lepidoptera: Plutellidae). — J. Biochem. 148: 189-200.

Liu Y.L., Guo H., Huang L.Q., Pelosi P. \& Wang C.Z. 2014: Unique function of a chemosensory protein in the proboscis of two Helicoverpa species. - J. Exp. Biol. 217: 1821-1826.

Liu S., Shi X.X., Zhu Q.Z., Jiao W.J., Zhu Z.J., Yu H., Wang G.Y. \& ZHU Z.R. 2015: Identification and expression profiles of putative chemosensory protein genes in Cnaphalocrocis medinalis (Lepidoptera: Pyralidae). - J. Asia-Pac. Entomol. 18: 99-105.

Liu H.L., Yang W.X., Hou J., Hu N., Yin T.M. \& Li S.X. 2016: Genetic identification of 43 elite clonal accessions of Populus deltoides by SSR fingerprinting. - Can. J. Plant Sci. 96: 494-502.

LivaK K.J. \& SchmitTGEN T.D. 2001: Analysis of relative gene expression data using real-time quantitative PCR and the 2(-delta delta $\mathrm{C}(\mathrm{T})$ ) method. - Methods 25: 402-408.
MaleszKa J., Forêt S., Saint R. \& MaleszKa R. 2007: RNAi-induced phenotypes suggest a novel role for a chemosensory protein CSP5 in the development of embryonic integument in the honeybee (Apis mellifera). — Dev. Genes Evol. 217: 189-196.

Mckenna M.P., Hekmat-Scafe D.S., Gaines P. \& Carlson J.R. 1994: Putative Drosophila pheromone-binding proteins expressed in a subregion of the olfactory system. - J. Biol. Chem. 269: 16340-16347.

Mei T., Fu W.B., Li B., He Z.B. \& Chen B. 2018: Comparative genomics of chemosensory protein genes (CSPs) in twentytwo mosquito species (Diptera: Culicidae): Identification, characterization, and evolution. - PLoS ONE 13(1): e0190412, 18 pp.

Min X.J., Butler G., Storms R. \& Tsang A. 2005: Orfpredictor: predicting protein-coding regions in est-derived sequences. Nucl. Acids Res. 33: W677-W680.

Muhammad I.W., Aneela Y., Muhammad T.Q., Liu H., Asif A., Sagib A., Hazem E.A., Zeng F.F. \& Wang M.Q. 2018: Silencing of chemosensory protein gene NlugCSP8 by RNAi induces declining behavioral responses of Nilaparvata lugens. Front. Physiol. 9: 379-396.

Pelosi P., Zhou J.J., Ban L.P. \& Calvello M. 2006: Soluble proteins in insect chemical communication. - Cell. Mol. Life Sci. 63: $1658-1676$.

Pelosi P., Iovinella I., Zhu J., Wang G. \& Dani F.R. 2017: Beyond chemoreception: diverse tasks of soluble olfactory proteins in insects. - Biol. Rev. Camb. Philos. Soc. 93: 184-200.

Petersen T.N., Brunak S., Von H.G. \& Nielsen H. 2011: SignalP 4.0: discriminating signal peptides from transmembrane regions. - Nat. Meth. 8: 785-786.

Picimbon J.F., Dietrich K., Krieger J. \& Breer H. 2001: Identity and expression pattern of chemosensory proteins in Heliothis virescens (Lepidoptera, Noctuidae). - Insect Biochem. Mol. Biol. 31: 1173-1181.

Qiao H.L., Deng P.Y., Li D.D., Chen M., Jiao Z.J., Liu Z.C., ZHANG Y.Z. \& KAN Y.C. 2013: Expression analysis and binding experiments of chemosensory proteins indicate multiple roles in Bombyx mori. - J. Insect Physiol. 59: 667-675.

Sangha K.S., Shera P.S. \& Makkar G.S. 2005: Biology of leaf defoliator, Clostera restitura (Walker) (Lepidoptera: Notodontidae) on poplar. - J. Insect Sci. 18: 47-51.

Schintlmeister A. 2008: Palaearctic Macrolepidoptera. Vol. 1: Notodontidae. Apollo Books, Stenstrup, 402 pp.

SingH G. \& SANGHA K.S. 2012: Ovipositional preference and larval performance of poplar defoliator, Clostera restitura on different poplar clones in north-western India. - J. Forestry Res. 23: 447-452.

Sower L., KaAe R.S. \& Shorey H.H. 1973: Sex pheromones of Lepidoptera. XLI. Factors limiting potential distance of sex pheromone communication in Trichoplusia ni. - Ann. Entomol. Soc. Am. 66: 1121-1122.

Sun L., Mao T., Zhang Y.X., Wu J.J., BaI J.H., Zhang Y.N., JiAnG X.C., Yin K.S., Guo Y.Y., Zhang Y.J. \& Xiao Q. 2017: Characterization of candidate odorant-binding proteins and chemosensory proteins in the tea geometrid Ectropis obliqua Prout (Lepidoptera: Geometridae). - Arch. Insect Biochem. Physiol. 94(9): e21283, 18 pp.

Tamura K., Peterson D., Peterson N., Stecher G., Nei M. \& KUMAR S. 2011: MEGA5: molecular evolutionary genetics analysis using maximum likelihood, evolutionary distance, and maximum parsimony methods. - Mol. Biol. Evol. 28: 2731-2739.

TANG F., WANG Y. \& GAO X. 2008: In vitro inhibition of carboxylesterases by insecticides and allelochemicals in Micromelalopha troglodyta (Graeser) (Lepidoptera: Notodontidae) and 
Clostera anastomosis (L.) (Lepidoptera: Notodontidae). - J. Agric. Urban Entomol. 25: 193-203.

Tegoni M., Campanacci V. \& Cambillau C. 2004: Structural aspects of sexual attraction and chemical communication in insects. - Trends Biochem. Sci. 29: 257-264.

ThOMPSON J.N. 1988: Evolutionary ecology of the relationship between oviposition preference and performance of offspring in phytophagous insects. - Entomol. Exp. Appl. 47: 3-14.

Tomaselli S., Crescenzi O., Sanfelice D., AB E., Wechselberger R., Angeli S., Scaloni A., Boelens R., Tancredi T. \& Pelosi P. ET AL. 2006: Solution structure of a chemosensory protein from the desert locust Schistocerca gregaria. - Biochemistry 45: 10606-10613.

Wang G.Y., Zhu M.F., Jiang Y.D., Zhou W.W., LiU S., Heong K.L., Cheng J. \& Zhu Z.R. 2017: Identification of candidate odorant-binding protein and chemosensory protein genes in Cyrtorhinus lividipennis (Hemiptera: Miridae), a key predator of the rice planthoppers in Asia. - Environ. Entomol. 46: 654-622.

Wanner K.W., Willis L.G., Theilmann D.A., Isman M.B., Feng Q. \& Plettner E. 2004: Analysis of the OS-D-like gene family. - J. Chem. Ecol. 30: 889-911.

Wu C.S. \& FAng C.L. 2003: Fauna Sinica, Insecta, Vol. 31, Lepidoptera: Notodontidae. Science Press, Beijing, 808 pp.

Xin Y., Qı J., Zhou X., Meı Y.H. \& Guo H.Z. 2017: Differential expression of chemosensory-protein genes in midguts in response to diet of Spodoptera litura.-Sci. Rep. 7: 296-317.

Xin H.Y., Zhang T., Han Y.H., Wu Y.F., ShI J.S., XI M.L. \& Jiang J.M. 2018: Chromosome painting and comparative physical mapping of the sex chromosomes in Populus tomentosa and Populus deltoides. - Chromosoma 127: 313-321.

Xu Y.L., He P., Zhang L., Fang S.Q., Dong S.L., Zhang Y.J. \& LI F. 2009: Large-scale identification of odorant-binding proteins and chemosensory proteins from expressed sequence tags in insects. - BMC Genomics 10: 632-645.

Yang K., He P. \& Dong S.L. 2014: Different expression profiles suggest functional differentiation among chemosensory proteins in Nilaparvata lugens (Hemiptera: Delphacidae). - Insect Sci. 14: 270, 8 pp.

Yi X., Liu X.L., Zhao H.M., Wang P.D., Rizwan-Ul-HaQ M., Hu M. \& ZHONG G.H. 2014a: Identification of a novel interacting partner of the chemosensory protein 1 from Plutella xylostella. —Int. J. Biol. Macromol. 63: 233-239.

Yi X., Wang P., Wang Z., Cai J., Hu M. \& ZhoNG G. 2014b: Involvement of a specific chemosensory protein from Bactrocera dorsalis in perceiving host plant volatiles. - J. Chem. Ecol. 40: $267-275$.

Zeng Y., Yang Y.T., Wu Q.J., Wang S.L. \& Zhang Y.J. 2018: Genome-wide analysis of odorant-binding proteins and chemosensory proteins in the sweet potato whitefly, Bemisia tabaci. - Insect Sci. 26: 620-634.

Zhang Z.Z. 1997: Forest Entomology. China Forestry Press, Beijing, $491 \mathrm{pp}$.

Zhang Y., Dong X., Liu J., Hu M., Zhong G., Geng P. \& Yi X. 2012: Molecular cloning, expression and molecular modeling of chemosensory protein from Spodoptera litura and its binding properties with Rhodojaponin III. - PLoS ONE 7(10): e47611, $10 \mathrm{pp}$.

Zhang Y.N., Jin J.Y., Jin R., Xia Y.H., Zhou J.J., Deng J.Y. \& Dong S.L. 2013: Differential expression patterns in chemosensory and non-chemosensory tissues of putative chemosensory genes identified by transcriptome analysis of insect pest the purple stem borer Sesamia inferens (Walker). - PLoS ONE 8(7): e69715, 19 pp.

Zhang Y.N, Ye Z.F., Yang K. \& Dong S.L. 2014: Antenna-predominant and male-biased CSP19 of Sesamia inferens is able to bind the female sex pheromones and host plant volatiles. Gene 536: 279-86.

Zhang Y.N., Zhu X.Y., Ma J.F., Dong Z.P., Xu J.W., Kang K. \& ZHANG L.W. 2017: Molecular identification and expression patterns of odorant binding protein and chemosensory protein genes in Athetis lepigone (Lepidoptera: Noctuidae). - Peer J. 5: e3157, $21 \mathrm{pp}$.

ZhU J.Y., Ze S.Z. \& YANG B. 2015: Identification and expression profiling of six chemosensory protein genes in the beet armyworm, Spodoptera exigua. - J. Asia-Pac. Entomol. 18: 61-66.

ZwIEBEL L.J. \& TAKKEN W. 2004: Olfactory regulation of mosquito-host interactions. - Insect Biochem. Mol. Biol. 34: 645-652.

Received March 31, 2019; revised and accepted September 23, 2019 Published online November 6, 2019

Supplementary material follows (Tables S1-S3, Fig. S1). 
Table S1. Oligonucleotide primers used for cloning ORFs and in the expression Analyses of CresCSPs.

\begin{tabular}{|c|c|c|c|}
\hline Primer name & Primer sequence $\left(5^{\prime} \rightarrow 3^{\prime}\right)$ & & \\
\hline \multicolumn{4}{|l|}{ Specific primers for cloning CSP ORFs } \\
\hline CSP1F & ATGAATCTACTAGTTTTATG & & \\
\hline CSP1R & TTAGTCATCACGGGCTAGGA & & \\
\hline CSP2F & ATGAAGTCCGTAGTTCTGTG & & \\
\hline CSP2R & TTATACGTGTCTTAGATCAC & & \\
\hline CSP4F & ATGAAGGTACTAGCTATTCT & & \\
\hline CSP4R & TTAATTTTTGACTGCTTCGA & & \\
\hline CSP5F & ATGAAGTTCTTCATAATGAC & & \\
\hline CSP5R & TTAGTCCGTCCCCAGAAGGA & & \\
\hline CSP6F & ATGAAGGTTTTATTACTCAC & & \\
\hline CSP6R & TTAATTTCСTTCCAATAAGT & & \\
\hline CSP7F & ATGAACACATTACTAGTCTT & & \\
\hline CSP7R & TTACTTTGATCCCTTAATGT & & \\
\hline CSP8F & ATGAAGGTCGCATTCTGCGT & & \\
\hline CSP8R & TTAATCTTTCTTCATTAACT & & \\
\hline Specific primers to determine expression patterns & & Amplification efficiencies & R2 \\
\hline RPS13-F & CGCACCTGGTAAGGGTATTT & $95 \%$ & 0.997 \\
\hline RPS13-R & CACCAATTTGTGAGGGGAGTG & & \\
\hline CSP1qRT-F & AGCGCACGGCAAATTGTGAA & $95 \%$ & 0.996 \\
\hline CSP1qRT-R & CACGGGCTAGGAAAGCTTCG & & \\
\hline CSP2qRT-F & CCTTGGCAACTCACGACTGC & $96 \%$ & 0.995 \\
\hline CSP2qRT-R & CTTGTGCCAGCGCTTCTCTG & & \\
\hline CSP4qRT-F & GTGGCAGTGTACGCCAAACC & $95 \%$ & 0.996 \\
\hline CSP4qRT-R & AGGAGTGCATCGGCCTTTGT & & \\
\hline CSP5qRT-F & TGCCGAGTTCAGAAAGCTGGT & $97 \%$ & 0.996 \\
\hline CSP5qRT-R & TCGCTTAGGGCCTTGACAGT & & \\
\hline CSP6qRT-F & СCTGTGTCTGGCTACGGCTT & $98 \%$ & 0.996 \\
\hline CSP6qRT-R & GCAGTACACGGCCCTTGAAAC & & \\
\hline CSP7qRT-F & AGCGCACGGCAAATTGTGAA & $96 \%$ & 0.996 \\
\hline CSP7qRT-R & CACGGGCTAGGAAAGCTTCG & & \\
\hline CSP8qRT-F & AAGTTGAAGGACGCCGTGGA & $95 \%$ & 0.996 \\
\hline CSP8qRT-R & GCGCGTTGCTCTGAAGTACA & & \\
\hline
\end{tabular}

Table S2. Summary of CSP genes identified in C. restitura.

\begin{tabular}{|c|c|c|c|c|c|c|c|c|c|c|}
\hline \multirow{2}{*}{$\begin{array}{l}\text { Gene } \\
\text { name }\end{array}$} & \multirow{2}{*}{ Acc. no. } & \multirow{2}{*}{$\begin{array}{l}\text { ORF } \\
\text { (bp) }\end{array}$} & \multirow{2}{*}{$\begin{array}{c}\text { Signal } \\
\text { peptide }\end{array}$} & \multirow{2}{*}{$\begin{array}{c}\text { Isoelectric } \\
\text { point }\end{array}$} & \multirow{2}{*}{$\begin{array}{c}\text { Molecular } \\
\text { weight }(k D a)\end{array}$} & \multicolumn{5}{|c|}{ Best blastx match } \\
\hline & & & & & & Species & Gene & Acc. no. & E-value & Identity (\%) \\
\hline CSP1 & MG518396 & 372 & 18 & 5.72 & 14.39 & Spodoptera litura & CSP3 & ALJ30214.1 & $5 e-56$ & 64 \\
\hline CSP2 & MG518397 & 378 & 17 & 8.58 & 14.16 & Spodoptera litura & CSP5 & ABM67688.1 & $1 e-50$ & 70 \\
\hline CSP4 & MG518399 & 381 & 17 & 6.73 & 14.49 & Bombyx mori & CSP10 & XP_012549237.1 & $5 e-68$ & 79 \\
\hline CSP5 & MG518400 & 369 & 18 & 5.17 & 13.87 & Spodoptera exigua & CSP16 & АKT26491.1 & $5 e-62$ & 72 \\
\hline CSP6 & MG518401 & 366 & 16 & 5.35 & 13.68 & Bombyx mori & CSP2 & AFF18035.1 & $7 e-46$ & 65 \\
\hline CSP7 & MG518402 & 387 & 17 & 8.21 & 14.73 & Athetis dissimilis & CSP9 & AND82451.1 & $3 e-56$ & 68 \\
\hline CSP8 & MG518403 & 321 & 18 & 5.85 & 11.81 & Helicoverpa armigera & CSP7 & AEX07268.1 & $2 e-10$ & 39 \\
\hline
\end{tabular}


Table S3. Sequences used in the alignment and phylogenetic tree construction.

\begin{tabular}{|c|c|c|c|}
\hline Gene & Name & Species & Accession number \\
\hline CresCSP1 & chemosensory protein 1 & Clostera restitura & MG518396 \\
\hline CresCSP2 & chemosensory protein 2 & Clostera restitura & MG518397 \\
\hline CresCSP3 & chemosensory protein 3 & Clostera restitura & MG518398 \\
\hline CresCSP4 & chemosensory protein4 & Clostera restitura & MG518399 \\
\hline CresCSP5 & chemosensory protein5 & Clostera restitura & MG518400 \\
\hline CresCSP6 & chemosensory protein 6 & Clostera restitura & MG518401 \\
\hline CresCSP7 & chemosensory protein 7 & Clostera restitura & MG518402 \\
\hline CresCSP8 & chemosensory protein8 & Clostera restitura & MG518403 \\
\hline BmorCSP1-2 & chemosensory protein CSP1 & Bombyx mori & AF509239.1 \\
\hline BmorCSP1 & chemosensory protein 1 & Bombyx mori & DQ855507.1 \\
\hline BmorCSP10 & chemosensory protein 10 & Bombyx mori & AB243753.1 \\
\hline BmorCSP10 & chemosensory protein 10 & Bombyx mori & DQ855516.1 \\
\hline BmorCSP11 & chemosensory protein 11 & Bombyx mori & DQ855517.1 \\
\hline BmorCSP11-2 & chemosensory protein CSP 11 & Bombyx mori & AB243754.1 \\
\hline BmorCSP13 & chemosensory protein 13 & Bombyx mori & DQ855519.1 \\
\hline BmorCSP14 & chemosensory protein 14 & Bombyx mori & DQ855520.1 \\
\hline BmorCSP15 & chemosensory protein 15 & Bombyx mori & DQ855521.1 \\
\hline BmorCSP16 & chemosensory protein16 & Bombyx mori & DQ855522.1 \\
\hline BmorCSP2-2 & chemosensory protein CSP2 & Bombyx mori & AF509238.1 \\
\hline BmorCSP2 & chemosensory protein2 & Bombyx mori & DQ855508.1 \\
\hline BmorCSP3-2 & chemosensory protein CSP3 & Bombyx mori & AB243746.1 \\
\hline BmorCSP3 & chemosensory protein 3 & Bombyx mori & DQ855509.1 \\
\hline BmorCSP4-2 & chemosensory protein CSP4 & Bombyx mori & AB243747.1 \\
\hline BmorCSP4 & chemosensory protein 4 & Bombyx mori & DQ855510.1 \\
\hline BmorCSP5-2 & chemosensory protein CSP5 & Bombyx mori & AB243748.1 \\
\hline BmorCSP5 & chemosensory protein 5 & Bombyx mori & DQ855511.1 \\
\hline BmorCSP6-2 & chemosensory protein CSP6 & Bombyx mori & AB243749.1 \\
\hline BmorCSP6 & chemosensory protein 6 & Bombyx mori & DQ855512.1 \\
\hline BmorCSP7-2 & chemosensory protein CSP7 & Bombyx mori & AB243750.1 \\
\hline BmorCSP7 & chemosensory protein 7 & Bombyx mori & DQ855513.1 \\
\hline BmorCSP8-2 & chemosensory protein CSP8 & Bombyx mori & AB243751.1 \\
\hline BmorCSP8 & chemosensory protein8 & Bombyx mori & DQ855514.1 \\
\hline BmorCSP9-2 & chemosensory protein CSP9 & Bombyx mori & AB243752.1 \\
\hline BmorCSP9 & chemosensory protein 9 & Bombyx mori & DQ855515.1 \\
\hline EhipCSP13 & chemosensory protein 13 & Eogystia hippophaecolus & KX655948.1 \\
\hline EhipCSP14 & chemosensory protein 14 & Eogystia hippophaecolus & KX655949.1 \\
\hline EhipCSP15 & chemosensory protein 15 & Eogystia hippophaecolus & KX655950.1 \\
\hline EhipCSP17 & chemosensory protein 17 & Eogystia hippophaecolus & KX655952.1 \\
\hline EhipCSP18 & chemosensory protein 18 & Eogystia hippophaecolus & KX655953.1 \\
\hline EhipCSP2 & chemosensory protein2 & Eogystia hippophaecolus & KX655937.1 \\
\hline EhipCSP3 & chemosensory protein 3 & Eogystia hippophaecolus & KX655938.1 \\
\hline EhipCSP4 & chemosensory protein4 & Eogystia hippophaecolus & KX655939.1 \\
\hline EhipCSP6 & chemosensory protein 6 & Eogystia hippophaecolus & KX655941.1 \\
\hline EhipCSP7 & chemosensory protein7 & Eogystia hippophaecolus & KX655942.1 \\
\hline GmolCSP11 & chemosensory protein 11 & Grapholita molesta & KR003783.1 \\
\hline GmolCSP3 & chemosensory protein 3 & Grapholita molesta & KR003780.1 \\
\hline GmolCSP8 & chemosensory protein8 & Grapholita molesta & KR003781.1 \\
\hline GmolCSP9 & chemosensory protein 9 & Grapholita molesta & KR003782.1 \\
\hline HarmCSP21 & chemosensory protein 21 & Helicoverpa armigera & KY810185.1 \\
\hline HarmCSP22 & chemosensory protein 22 & Helicoverpa armigera & KY810186.1 \\
\hline HarmCSP23 & chemosensory protein 23 & Helicoverpa armigera & KY810187.1 \\
\hline HarmCSP25 & chemosensory protein 25 & Helicoverpa armigera & KY815026.1 \\
\hline HarmCSP26 & chemosensory protein 26 & Helicoverpa armigera & KY815027.1 \\
\hline HassCSP & chemosensory protein & Helicoverpa assulta & DQ285667.1 \\
\hline HassCSP20 & chemosensory protein 20 & Helicoverpa assulta & KY810189.1 \\
\hline HassCSP21 & chemosensory protein 21 & Helicoverpa assulta & KY810190.1 \\
\hline HassCSP22 & chemosensory protein 22 & Helicoverpa assulta & KY810191.1_ \\
\hline HassCSP23 & chemosensory protein 23 & Helicoverpa assulta & KY810192.1 \\
\hline HassCSP24 & chemosensory protein 24 & Helicoverpa assulta & KY810193.1 \\
\hline HassCSP25 & chemosensory protein 25 & Helicoverpa assulta & KY810194.1 \\
\hline HvirCSP2 & chemosensory protein 2 & Heliothis virescens & AY101511.1 \\
\hline HvirCSP1 & chemosensory protein 1 & Heliothis virescens & AY101512.1 \\
\hline LbotCSP10 & chemosensory protein 10 & Lobesia botrana & MG788191.1 \\
\hline LbotCSP13 & chemosensory protein 13 & Lobesia botrana & MG788194.1 \\
\hline LbotCSP14 & chemosensory protein 14 & Lobesia botrana & MG788195.1 \\
\hline LbotCSP18 & chemosensory protein 18 & Lobesia botrana & MG788196.1 \\
\hline LbotCSP19 & chemosensory protein 19 & Lobesia botrana & MG788197.1 \\
\hline LbotCSP2 & chemosensory protein2 & Lobesia botrana & MG788184.1 \\
\hline LbotCSP20 & chemosensory protein 20 & Lobesia botrana & MG788198.1 \\
\hline LbotCSP21 & chemosensory protein 21 & Lobesia botrana & MG788199.1 \\
\hline LbotCSP23 & chemosensory protein 23 & Lobesia botrana & MG788201.1 \\
\hline LbotCSP3 & chemosensory protein 3 & Lobesia botrana & MG788185.1 \\
\hline LbotCSP4 & chemosensory protein 4 & Lobesia botrana & MG788186.1 \\
\hline LbotCSP5 & chemosensory protein5 & Lobesia botrana & MG788187.1 \\
\hline LbotCSP6 & chemosensory protein 6 & Lobesia botrana & MG788188.1 \\
\hline OfurCSP1 & chemosensory protein 1 & Ostrinia furnacalis & LC027702.1 \\
\hline OfurCSP10 & chemosensory protein 10 & Ostrinia furnacalis & LC027711.1 \\
\hline OfurCSP12 & chemosensory protein 12 & Ostrinia furnacalis & LC027713.1 \\
\hline OfurCSP13 & chemosensory protein 13 & Ostrinia furnacalis & LC027714.1 \\
\hline
\end{tabular}


Table S3 (continued).

\begin{tabular}{|c|c|c|c|}
\hline Gene & Name & Species & Accession number \\
\hline OfurCSP16 & chemosensory protein 16 & Ostrinia furnacalis & LC027717.1 \\
\hline OfurCSP2 & chemosensory protein 2 & Ostrinia furnacalis & LC027703.1 \\
\hline OfurCSP4 & chemosensory protein 4 & Ostrinia furnacalis & LC027705.1 \\
\hline OfurCSP5 & chemosensory protein 5 & Ostrinia furnacalis & LC027706.1 \\
\hline OfurCSP6 & chemosensory protein 6 & Ostrinia furnacalis & LC027707.1 \\
\hline OfurCSP7 & chemosensory protein 7 & Ostrinia furnacalis & LC027708.1 \\
\hline OfurCSP8 & chemosensory protein 8 & Ostrinia furnacalis & LC027709.1 \\
\hline PxutCSP1 & chemosensory protein 1 & Papilio xuthus & AB260116.1 \\
\hline PxutCSP10 & chemosensory protein 10 & Papilio xuthus & $A B 260126.1$ \\
\hline PxutCSP11a & chemosensory protein $11 a$ & Papilio xuthus & AB430775.1 \\
\hline PxutCSP11b & chemosensory protein $11 \mathrm{~b}$ & Papilio xuthus & AB430776.1 \\
\hline PxutCSP12 & chemosensory protein 12 & Papilio xuthus & AB430777.1 \\
\hline PxutCSP13 & chemosensory protein 13 & Papilio xuthus & AB430778.1 \\
\hline PxutCSP2 & chemosensory protein2 & Papilio xuthus & AB260117.1 \\
\hline PxutCSP3 & chemosensory protein 3 & Papilio xuthus & AB260118.1 \\
\hline PxutCSP4 & chemosensory protein4 & Papilio xuthus & AB260119.1 \\
\hline PxutCSP4a & chemosensory protein $4 a$ & Papilio xuthus & AB430771.1 \\
\hline PxutCSP4b & chemosensory protein $4 \mathrm{~b}$ & Papilio xuthus & AB430772.1 \\
\hline PxutCSP4c & chemosensory protein4c & Papilio xuthus & AB430773.1 \\
\hline PxutCSP5 & chemosensory protein5 & Papilio xuthus & AB260120.1 \\
\hline PxutCSP6 & chemosensory protein 6 & Papilio xuthus & $A B 260121.1$ \\
\hline PxutCSP7 & chemosensory protein 7 & Papilio xuthus & AB260122.1 \\
\hline PxutCSP8 & chemosensory protein8 & Papilio xuthus & AB260123.1 \\
\hline PxutCSP8a & chemosensory protein8a & Papilio xuthus & AB260124.1 \\
\hline PxutCSP8b & chemosensory protein8b & Papilio xuthus & AB430774.1 \\
\hline PxylCSP1 & chemosensory protein CSP1 & Plutella xylostella & EF186791.1 \\
\hline PxylCSP2 & chemosensory protein CSP2 & Plutella xylostella & EF186792.1 \\
\hline PxylCSP3 & chemosensory protein CSP3 & Plutella xylostella & EF202828.1 \\
\hline PxylCSP4 & chemosensory protein CSP4 & Plutella xylostella & EF202829.1 \\
\hline PxylCSP5 & chemosensory protein 5 & Plutella xylostella & EF202830.1 \\
\hline SexiCSP1-1 & chemosensory protein 1 & Spodoptera exigua & KM275345.1 \\
\hline SexiCSP1 & chemosensory protein 1 & Spodoptera exigua & EF186793.1 \\
\hline SexiCSP2-1 & chemosensory protein 2 & Spodoptera exigua & KM275346.1 \\
\hline SexiCSP2 & chemosensory protein 2 & Spodoptera exigua & EF186794.1 \\
\hline SexiCSP3-1 & chemosensory protein 3 & Spodoptera exigua & KM275347.1 \\
\hline SexiCSP3 & chemosensory protein 3 & Spodoptera exigua & EF186795.1 \\
\hline SexiCSP6 & chemosensory protein 6 & Spodoptera exigua & KM275350.1 \\
\hline SlitCSP & chemosensory protein & Spodoptera litura & DQ007458.1 \\
\hline
\end{tabular}

Fig. S1. Alignment of mature CresCSPs and CSPs of other Lepidoptera. Amino acids conserved in all CSPs are shown with a black background. The sequences used in the construction of this phylogenetic tree are listed in Table S3. 
Crescsp 1

Crescsp2

Crescsp 3

Crescsp 4

CresCSP5

Crescsp6

CresCSP7

Crescsp

HcirCSP2

BvirCSP1

HvirCSP1

Pxy1CSP3

Pxy1CSP

Pxy1CsP2

BMorCSP2

HarMCSP26

HarMCSP25

HassCSP25

HassCSP24

HassCSP 23

HassCSP22

Hasscsp21

Hercse 22

HarMCSP23

HarMCSP21

GMo1CSP11

GMolCSP

GMOICSP3

OfurCSP16
OfurcsP13

Ofurcsp13

ofurcsp10

OfurCsP

Ofurcsp?

OfurCSP6

OfurCsp5

Ofurcsp2

PxutCSP10

Pxutcsp8a

Pxutcspa

Pxutcse

Pxutcs

Pxutcse

Pxutcsp3

Pxutcsp2

PxutCSP1

Pxutc5P4a

PxutcsP4c

PxutCSP8b

PxutCSP11a
PxutCSP11b

PxutCSP12

PxutCSP13

BMorCSP11

BMorCSP9

BMoresp

BMorCSP?

BMorcs.

BMoress

BMorcsp3

Sexicsp

Sexicsp1

Sexicsp

Sexicsp

LbotCSP23

LbotCSP21

LbotCSP20

LbotCSP19
LbotCSP18

LbotCS18

LbotCSP13

LbotCSP10

IbotCSP6

Lotcs

Ibotc5

Ibotc58

Pxy1C5P5

Sexicsp3-2
Sexicsp2-2

Sexicsp1-2

BMorCSP16

BMorCSP15

BMorCSP14

BMorCSP13

BMorCSP11-2

BMorCSP10

BMorCSP9-2
BMorCSP8-2

BMorCSP8-2
BMorCSP7-2

BMorCSP6-

BMorCSP5-2

BMorCSP4-

BMorCSP $3-2$

BMorCSP2-2

HassCSP

Slitcse

EhipCSP18

EhipCSP17

EhipCSP15

hipCSP14

hipCsp13

EhipCSP7

EhipCSP6

EhipCSP4

EhipCSP3

EhipCSP2

..........MN ...ILVLCFVVAFASLAAT ....ETY MRS. .VVLCVIGLAALAVAFPG.G.DM .MRG.AIVFCLIAVATIAVARE.... DKY MRVLAIL.ALTCLVAV. YAREQ $\ldots$...STY ..MREF IMTLMAISTPFVLG....... Y .MR ...VLLLLTLCLATALVAEE...... IY ........MN...TLIVECIITVVAVSAREN ....EQ EY ........................... . M. RVLIVLSCVLVAVLADE .....K

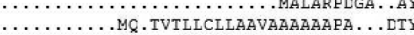
. . ....MN . . SIVLVCLALVAVAAAREQ ....ATY . ..............MRSAAFI. . ALFLIGRAVCEDR . ... PTY . .............MR. SLIILCLVI . . AAAVWARP.... ETY (.........MNS.LIVECVVSLAALTIARPDGA...TY ..........MNS.AIVLCVVALAGMVLARPDGG ...TY ........MRITVAV. ALICLVAESWAAS...... $\ldots \ldots \ldots$ MR. IIIVIALVAVV. AARF. DE ....AFY . $\ldots \ldots \ldots \ldots$ MNS. AIVLCVVALAGMVLARPDGG . . TY

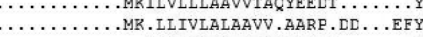
$\ldots \ldots \ldots \ldots \ldots$ MRVIMVAVLALVAAPSALG $\ldots \ldots \ldots$. . . . .....MNS.AIVLCVVALAGMVLAREDGDGDKY $\ldots \ldots \ldots \ldots$ MI ... IASLALISA . . . ISTVTA . . . DFY

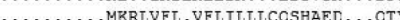
$\ldots \ldots \ldots \ldots$ MM. LKYEVVICVASWALADE $\ldots \ldots$ KY .......MSHRRVLVLSHLMVELCVQCEA .....

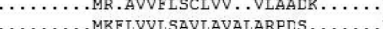
$\ldots \ldots \ldots$ MRT IMIVAE. IVGLAMADER ......... ..........MRIVAF IPTF TYLLIGANAEES . ... PTY .........MR ... TFAICLLLALVAVVSAYYQ ....ARY ..........MR ... IVIISICLAAAVVACE . . ....RY . .

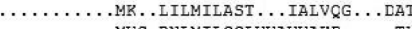

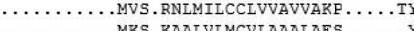
$\ldots \ldots \ldots \ldots$ MR $\ldots$. IIVLVLCVTALAYAED $\ldots \ldots$ RY ..................... . .....................

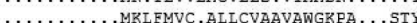
$\ldots \ldots$ MN ... SLILFSLLTI FVVAEAN ... FGY $\ldots \ldots \ldots$ MRS. VVLLCL FVVLATAVAGEA $\ldots$ GQY . .

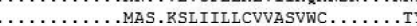
$\ldots \ldots \ldots \ldots$ MRTIVALTV. IVGLATTALA $\ldots \ldots \ldots$ . MRCILILPM. . LMALVAAET . ........ . MVF LSLVLAMLIPTALS . . ....... $\ldots \ldots \ldots \ldots$ MR.. QWLLCVFALTVVVSCSS $\ldots$. QQQY $\ldots \ldots \ldots \ldots$ MRGFYVICFALFAAVYCRET...$\cdots$.... ............MRAVTFLYTCVWVVGELTNAMSSMPK ..........MR.SLIVLSCLLAA.CLAAD, . ...............

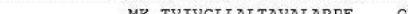
MR.TVIVCLLALTAVALAREE $\ldots .$. MN..........MACVAVT. WAREE ....STY $\ldots \ldots \ldots \ldots$ MN . . FLVLSIVVTMAAFVAA .... ETY

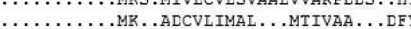
$\ldots \ldots \ldots \ldots$ MRVIVVISVF LALTTAVPLTRE.....

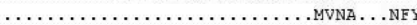
...............MWGLFILALTVVATSSA ... QQQYY ..........MRAV. FVEACVT FVVAQLDINSVRDL PKY ...............VIVFACLLAVVVSARPG ... DKY .........MNS. ELIVCVFALAAVAYAREG ....DTY $\ldots \ldots \ldots \ldots$ MR ....ILLIFCCG.IVGLSLAD $\ldots$.. DI

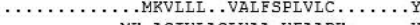
.................... $\ldots \ldots \ldots \ldots$.MR. TVIILMIVG ... LAASREE $\ldots$. EG . ................ ............. IIIIISIGI EAGTMAG ......... $\ldots \ldots \ldots \ldots$ MR . . VVFLVFVLTAVVYSHPHDS. . HY ...........MRS.MIVLCVISVAALVVAREDDS...HY MRS. ETVICIEGTARVAMARPD. G. STY .....MIEWR. RERILHFLSYLGLLVLVVVCAAC . .... MIENFYSRCT. ISRSVLFICL IFL PYALNQRY . . . . . .............MR . SSLECVIVLTVVVSSS..... RQCQS

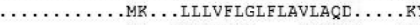
...........MR . . LTSELLVG .....MAMVSA ....EFY ...........MRILIIV. VMACVAVT. WARPE... STY $\ldots \ldots \ldots \ldots$ MRAVIF LYTCVEVVVGG DINAMMSMPRY ...........MR. TILILCALVS. . VVVCREE . . . EYY $\ldots \ldots \ldots \ldots \ldots$ MRG YVICEAIF AAVYCREI

.......................... .

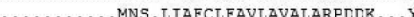
..........MRS.VILICF LGVATVVIARE. . . . . ................ CITIAALLLFVAGLSIA ....ERY $\ldots \ldots \ldots \ldots \ldots$.RVLLVICLEAAAVIADD . .....KY $\ldots \ldots \ldots \ldots \ldots$ MR... . SICTVILFV... ISIVYA . . . DFY $\ldots \ldots \ldots \ldots$ MRT . F IVVCF FALVAIATALIPG . . . ARY ..........MR...NWLICLCALTVVVSCSG ... \&QQ ............MIM.RCVIALICVLGMVIALE......R ............MR.VLIVLACLGVA.AYAAER ....... ...........

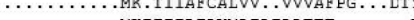
............MRIFIIL FAVMAIAIAAEET $\ldots . . . \cdots$

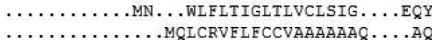




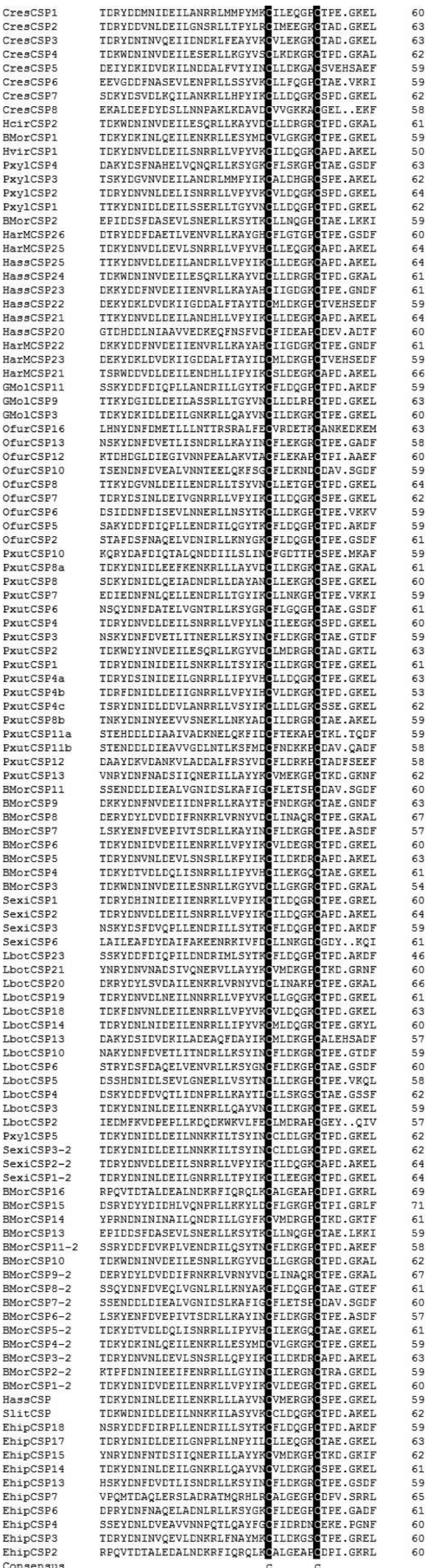




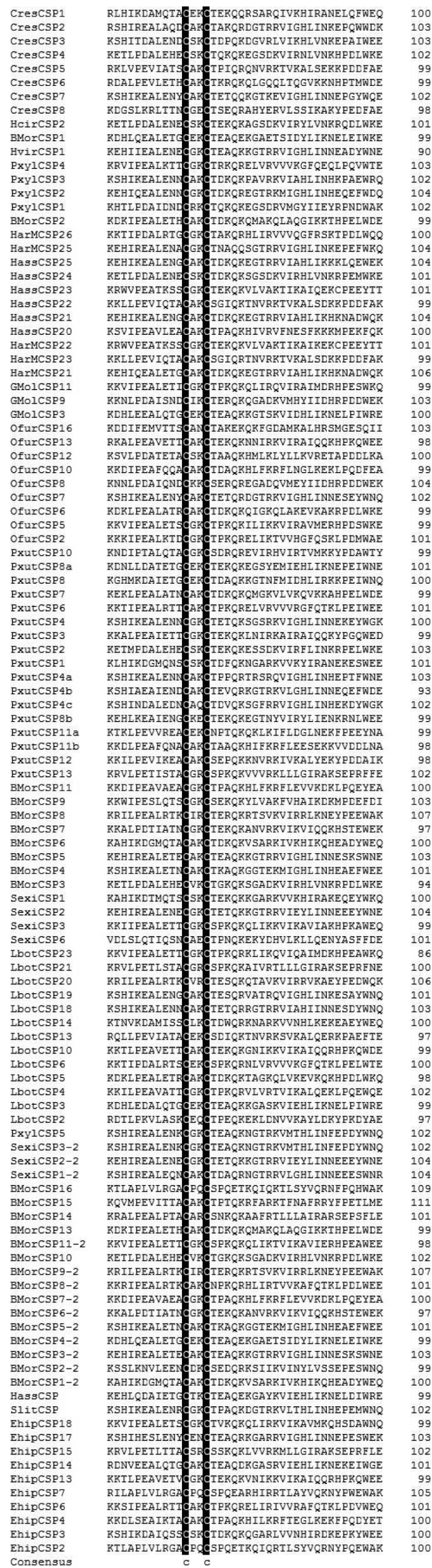


CrescsP1

CrescSP2

CrescSP3

Crescsp 4

Crescsp5

CrescsP6

CresCSP7

CrescSP8

BMorCsP1

BMorCSP1
HvirCSP1

Pxyicsp4

Pxy1CSP4
Pxy1CSP3

PxylCsp3
Pxyicsp2

Pxy1CsP1

BMorCSP2

HarMCSP26
HarMCSP25

assCSP2

HassCSP2

HassCSP23

HassCSP22

HassCSP21

HassCSP20

HarMCSP22

HarMCSP23

GarMCSP21

GMOICSP9

GMolCSP3

OfurCsP1

OfurCSP13

ofurcsP12

OfurCSP10

OfurCSP8

ofurCSP7

ofurCSP 6

ofurcsp5

ofurCSP2

PxutCSP10

Pxutcsp8a

PxutCSP8

PxutCSP7

PxutcSP6

PxutCSP4

Pxutcsp3

PxutcSP1

Pxutcss

PxutCSP4a

PxutcsP4c

PxutCSP8b

exutcsP11a

PxutCSP11b

PxutCSP12

PxutCSP13

BMorCSP11

BMorCSP9

BMorCSP8

BMorCSP7

BMorCSP6

BMorCsP5

3)

列

SexicsP1

SexicsP2
Sexicsp3

Sexicsp3

SexiCSP6
LbotcSP23

LbotCSP21

LbotCSP2

LbotCSP19

LbotCSP18

LbotCSP14

LbotCSP13

LbotCSP10

LbotCSP6

LbotCSP5

LbotCSP4

LbotCSP3

LbotCSP2

PxylCSP5

SexicsP3-2

SexiCSP1-2

BMorCSP16

BMorCSPI

BMorCSP15

BMorCSP13

BMorCSP11-

BMorCSP10

BMorCSP9

BMorCSP8-2

BMorCSP7-2

BMorCSP 6-2

BMorCSP5-2

BMorCSP4-2

MOICSPJ-2

$3 \mathrm{Mos}-2$

HassCSP

HassCSP

EhipCSP18

EhipCSP18

EhipCSP15

EhipCSP14

EnipCSP13

EhipcSP7

EhipCSP6

EhipCSP4

EhipCSP3

EhipCSP2

Consensus

VRARYLPGLREKETYEAFLARDD

RARYDARGLYSRKYESDLRHV. . .

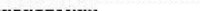

.

HYDPNGKYCDAFRDLIEGN

RYDSEGKYVHKYFDEIRHTRGSR .

RLMRRL. .

YYDPNNIYQDRYRDKIEAVRG

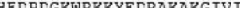

FDPERRYVQRYERELREVRA

SKEDPRGEYKDSFARFLEGS. . .

W. 126

IFRKYLSDGSYKKKYIEKRNASENNGDSRSTEARNKDDE

ITFYDPCGKYQTSFRDFLES...

LVRKEDPNGQYKEVETRFLNGSD . .

LNAKYDPNNKYTKKYEKELREV QEEEH

LRAKYDPE GRYARKYERELEEVVNA . ...

IDPENKYAEDLRNYLARYGH..

FRARE DPRGEYERDF SAFMLATD.

BNRYDPEGRYFDNFEAAVAAF.....

IRQIDPENKYADDLRNYLARYGH

DRTY

TRM

DSDGSYRQKYIDSREHKEERATESERPAENENAVE

SARE D PEGKERKTYE $Q R A R E H G I T I P E E . \cdots \ldots \ldots$.

TME INRMTNME QGGLSDTERT . .

RYDP SKHIDALIAAIRDA...

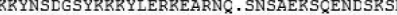

LRE DRDKRERDSFNRFLEER .

IVRKHDPEGQYTESF DAFLNSK . .

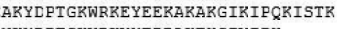

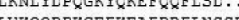

.

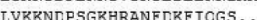

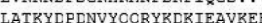

MRKRYD PKDEYKEKYEAFLAADN...

ICQRYDPTSEYTRKYFFELRTIAZ . .

ITARYDPEHKYSVKYENELRTSK . .

ITAKYDPERKYVLKYERDIREISA .

FLPGKWRKHYEEEAKAKGIKI.

RRQEDPTGRLFEALNAALARA. .

RRYDPESRHYAALISAISRS .

.

FRTKYDPRGKHFDALISAVANS..

LASRWDPTGDFTRYFEDYLAREHFNTI I GSGETVNVLSL

LVRKHLPSGRHRALF LRFLLGS...

.

LTARYDFENATARERELREIRA.

LRA

JURY

ITAKYDPERKYTAKYEREIRKIKA ...

MCKMATKKE ...

LICRYDPENRRREDFDRFLSENK

LASRWDPIGLFTRYFEEVLTRDHFNTIPNSNEIPGSSPL

LVIRYLSCRRKYVAKYESEIRAVRA ...

CVRYLPLRKYVIRYESELRTVRA.....

MARYLPGLVHKASYEAFISRSD.

FRARYDPRGEYEQRKFAAF ILES .

URANDTGRYANFNKFIDS. .

LVSKYDPSGKYHRSFEDFLRN. . . .

(n)

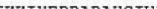

TXYEPRE . .

LCARYDEGRYRAIYEKEYRTLVH

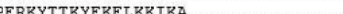

(S)

(1)

KRYYDAFEKVITNA

LDKYDFSRSNRELI YTFLATGI .

FITFYDFQGRYQTSFRDFLES. .

LVNRYDRDRRKRPSF DRF INED .

.

LARELPRGCYRHEFTAF INAMD.

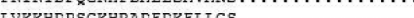

IVRRHDPSGRHRADFDKFLLGS.

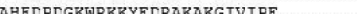

LTAHFPLGKWRKAYELRARARGIVI.'.

TARYLPENRTARYLRELREIRA.

YFFE IYEGELAGQN . .

LCERYDAE GRYRKMYEDEYRSVRH...

LNARYDPEHKYYTKKYEDELRTI

作

IVCKNDPSGKHRADF LRF IC्रSS. .

LARKEDPNGEYKESFEAFLNRSD $. . \ldots \ldots \ldots \ldots \ldots \ldots, \ldots$

LRIKYDPDDQYKEIYEAFLIARD . .

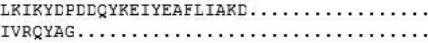

123

127

122

128

134
142

120

131

126

122

128

125

130

143

129

120
122

143

120

122

122

134

120

124
124

121

124

116

126

121

120

125
122

122

147

119
123

125

120
123

123
128

122

111

109
123

146
125

127
123

120

120

123
119

125

129
107

126
126

126

128

128
116

116

124
120

121
122

147

124

122

119
125

127
127

127
121

123
127
126

121
127

127
125

130

121

124

122
123

123
107 
Crescsp1

Crescsp2

CresCSP3

CresCSP4

CrescSP5

CrescSP6

CrescSP7

Crescsp8

cirCSP2

BMorCSP1

HvirCSP1

PxylCsP4
Pxylcsp3

PxylCsp3

Pxy1Csp1

BMorCSP2

HarMCSP26

HarMCSP25

HassCSP25

Hass CSP2 2

HassCSP23

HassCSP22

HassCSP21

HassCSP20

HarMCSP22

HarMCSP23

HarMCSP21

GMolCSP11

GMOICSP3

OfurCSP16

OfurCSP16

furcsP12

ofurCsP10

ofurCSPB

OfurCSP7

OfurCsP6

OfurCsP5

OfurCSP2

PxutCSP10

PxutCsP8a

PxutCSP8

PxutCSP7

PxutCSP6

PxutCSP4

PxutCSP3

PxutcSP1

PxutCSP4a

Pxutcsp4a
Pxutcsp4b

PxutcsP4c

PxutCSP8b

Pxutcsp11a

PxutCSP11b

PxutCSP12

PxutCsP13

BMorCSP11

BMorCSP9

BMorCSP8

BMorCSP7

BMorCSP6

BMorCSP5

BMorCSP4

BMorCSP3

SexicsP1

SexicsP2

SexicsP3
SexicsP6

LbotCSP23

LbotCSP21

LbotCSP20

LbotCSP19

LbotCSP18

LbotCSP14

LbotCSP13

LbotCSP10

LbotCSP6

LbotCSP5

LbotCSP4

LbotCSP3

LbotCSP2

PxylCSP5

SexicsP $3-2$

SexiCSP1-2

BMorCSP16

BMorCSP15

BMorCSP14

BMorCSP13

BMorCSP11-2

BMorCSP10

BMorCSP9-2
BMorCSP8-2

BMorCSP8-2

BMorCSP $7-2$

BMorCSP6-2

BMorCSP5- 2

(1)

MICsP 2

(

促

HassCSP
SlitCSP

EhipCSP18

EhipCSP18

EhipCSP15

EhipCSP14

thipCSP13

EhipCsP7

Ehipcsp6

Ehipcsp4

Ehipcsp3

EhipCSP2

Consensus

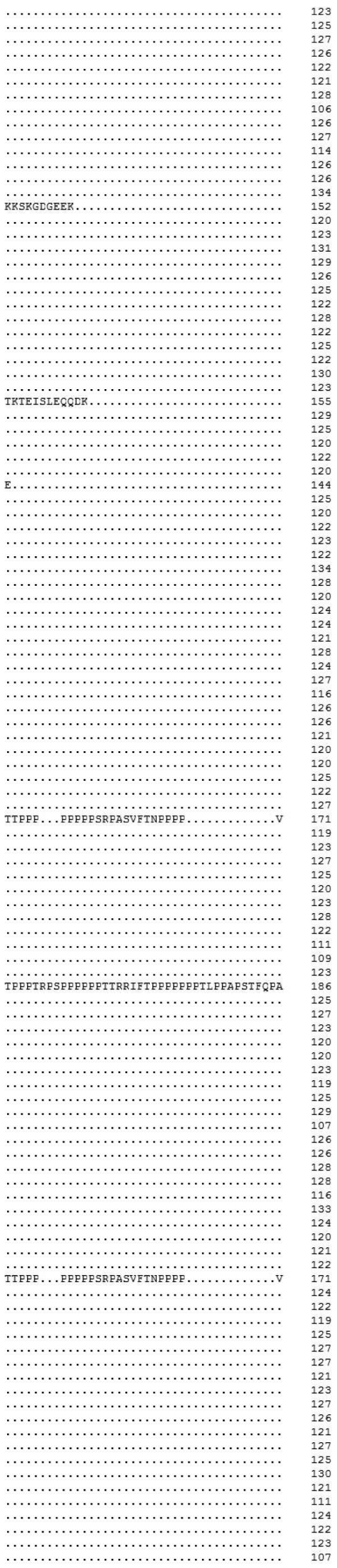


CresCSP1

Crescsp2

CresCSP3

Crescsp4

CresCSP5

CrescSP6

Crescsp7

Crescs

TorCsP1

HoirCSP1

Pxyicsp4

Pxylcsp4

PxylCsp3
Pxyicsp2

Pxy1CSP1

BMorCSP2

HarMCSP26

HarMCSP25

HassCSP25

HassCSP24

HassCSP23

HassCSP22

HassCSP21

Hasscsp 20

HarMCSP22

HarMCSP23

HarMCSP21

GMOICSP11

GMOICSP3

OfurCSP16

OfurCSP13

ofurCsP12

OfurCsP10

OfurCSP8

ofurCSP7

OfurCSP6

ofurCsP5

OfurCSP2

PxutCsP10

Pxutcsp8a

PxutCSP8

PxutCSP7

PxutCSP6

PxutCSP4

PxutCSP3

PxutCSP2

PxutCSP4a

PxutCSP4a

Pxutcsp4c

PxutCSP8b

Pxutcsp11a

PxutCSP11b

PxutCSP12

PxutCSP13

BMorCSP11

BMorCSP9

BMorCSP8

BMorCSP7

MorCSP6

4

Morcsp 4

Sexic5P1

SexicsP1
Sexicsp2

Sexicsp2

SexicSP6

LbotCSP23

LbotCSP21

LbotCSP20

botCSP19

LbotCSP18

LbotCSP14

LbotCSP13

LbotCSP10

LbotCSP6

LbotCSP5

LbotCSP4

LbotCSP3

LbotCSP2

Pxy1CSP5

SexicsP $3-2$
SexicsP2-2

SexiCSP1-2

SexiCSP1-2

BMorCSP15

BMorCSP14

BMorCSP13

BMorCSP11-2

BMorCSP10

BMorCSP9-2
BMorCSP8-2

BMorCSP7-2

BMorCSP6-2

BMorCSP5-2

BMOCSP4-2

MorCsp3-2

(c) 2

HassCSP
SlitCSP

FhipCSP1

EhipCSP18

hipCSP15

EhipCSP14

EhipCSP13

EhipCSP7

EhipCSP6

EhipCSP4

EhipCSP3

EhipCSP2

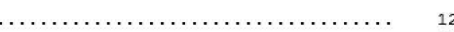

123

.

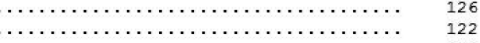

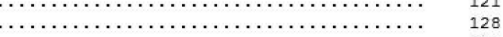

n.w.

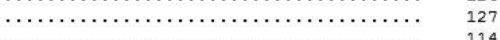

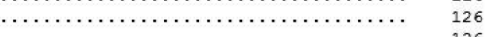

$\begin{array}{lll}* & 126 \\ - & 134\end{array}$

.

.

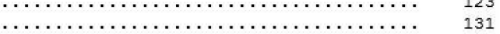

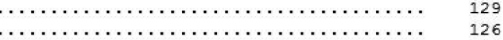

W.. 125

.

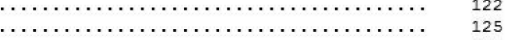

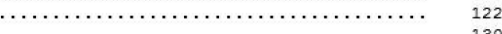

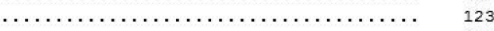

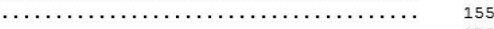

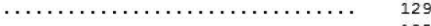

.

…

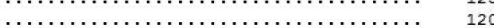

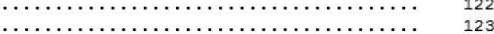

(122

122

.

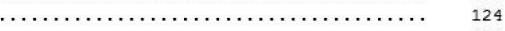

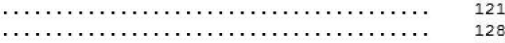

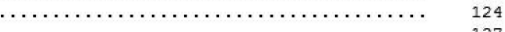

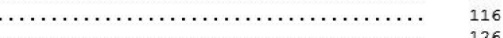

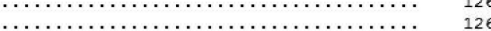

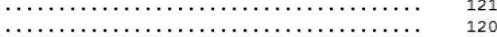

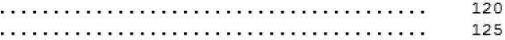

......................................... 127

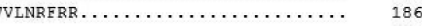

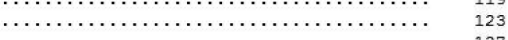

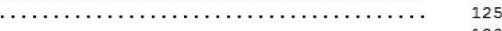

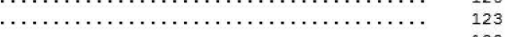

.



TISPRPVILMRFGLDGELMVNGCEAPTQNARPTTVRPVY

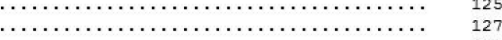

,

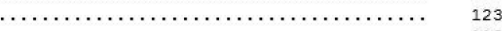

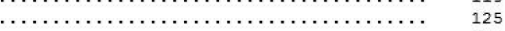

129

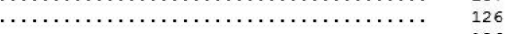

126

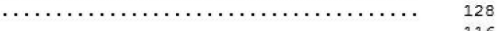

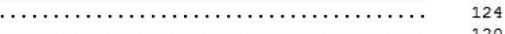

121

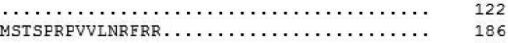

124

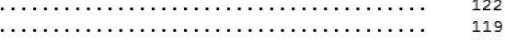

125

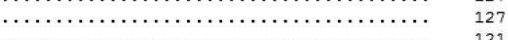

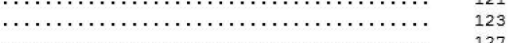

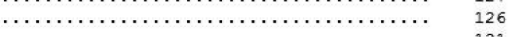

.

…

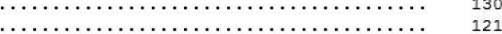

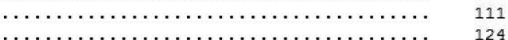

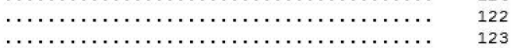

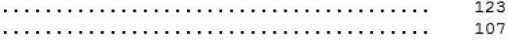


Crescsp1

Crescsp2

CresCSP3

Crescsp4

CrescSP5

CresCSP6

CrescSP7

Crescsp8

CrirCSP2

HirCSP1

Pxylcsp4

PxylCsp4

Pxy1CSP3
Pxyicsp2

PXy1CSP2
Pxy1CSP1

BMorCSP2

HarMCSP26

HarMCSP25

HassCSP25

HassCSP24

HassCSP23

HassCSP22

HassCSP21

Hasscsp20

HarMCSP22

HarMCSP23

HarMCSP21

GMoICSP11

GMOICSP3

GMo1CSP3

OfurCSP16
OfurCSP13

ofurCsP12

Ofurcsp10

ofurCSPB

OfurCSP7

OfurCSP6

Ofurcsp5

OfurCsP2

PxutCSP10

PxutCsP8a

PxutCSP8

PxutC5P7

PxutCSP6

PxutcSP4

PxutCSP3

PxutCSP2
PxutCSP1

PxutCSP4a

PxutCSP4a
PxutCSP4b

Pxutcsp4c

PxutCSP8b

Pxutcsp11a

PxutCSP11b

PxutCSP12

PxutCSP13

BMorCSP11

BMorCSP9

BMorCSP8

BMorCSP7

BMorCSP6

BMorCSP5

BMorCSP 4

BMorCSP3

SexiCSP1

SexicSP2

SexiCSP3
SexicsP6

LbotCSP23

LbotCSP21

LbotCSP20

bootCSP19

LbotCSP18

LbotCSP14

LbotCSP13

LbotCSP10

LbotCSP6

LbotCSP 5

LbotCSP4

LbotCSP3

LbotCSP2
Pxy1CSP5

Pxy1CSP5

SexicSP3-2
SexicSP2-2

SexicsP1-2

SexicSP1-2

BMorCSP15

BMorCSP14

BMorCSP13

BMorCSP11-2

BMorCSP10

MorCSP9-2

BMorCSP8-2

BMorCSP7-2

BMorCSP6-2

BMorCSP5-2

BMorCSP4-2

HMTS 2

Mesp

政

HassCSP

EhipCSP1

EhipCSP18

hipCsP15

EhipCsP14

EhipCSP13

hipCSP7

EhipCSP6

EhipCSP4

EhipCSP3

EhipCSP2

Consensus

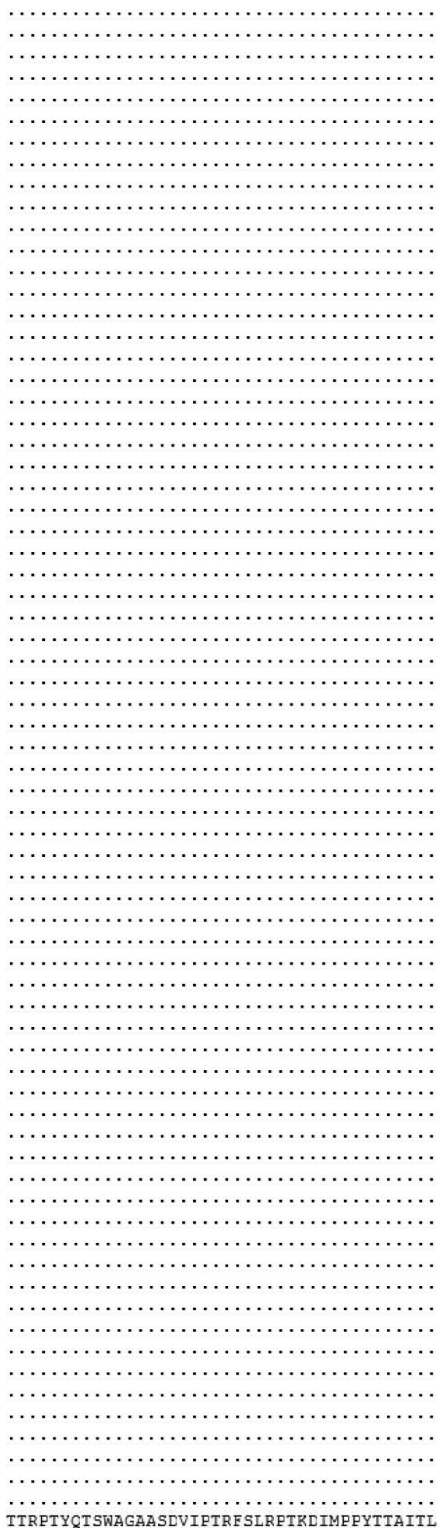

123

125

127
126

122

128

106

127

126

126
134

152

123

131
129

126

125

128

122

122

123

155

125

120

120

125

120
122

123

122

128

120

124

128

124

116

126

121

120

125

122
127

186

119

127

125

123

122

111
109

TTRPTYQTSWAGAASDVIPTRESLRETRDTMPPYTTAITL

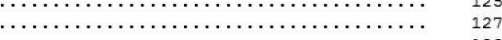

(120

(n.w.

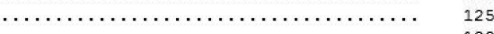

129

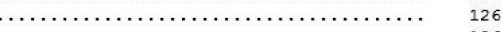

. ... ${ }_{124}$

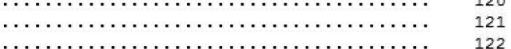

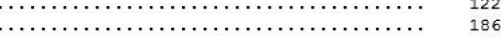
(n.

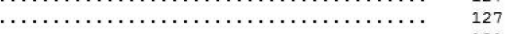
(n.w.

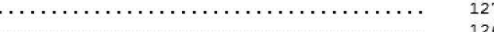
.

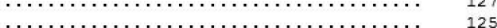
. …

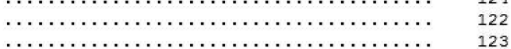

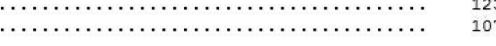


Crescsp1

Crescsp2

Crescsp3

CresCSP4

Crescsp5

CresCSP6

CrescSP7

CrescSP8
HсirCSP2

CirCSP2

HirCSP1

Pxy1CSP4

Pxyicsp4
Pxyicsp3

Pxy1CSP3
Pxyicsp2

PxyICSP2
Pxy1CSP1

BMorCSP2

HarMCSP26

HarMCSP25

HassCSP25

HassCSP2 24

HassCSP23

HassCSP22

HassCSP21

HassCSP 20

HarMCSP22

HarMCSP23

HarMCSP21

GMolCSP11

GMOICSP3

OfurCsP16

OfurCSP16
OfurCSP13

ofurCSP12

ofurCsP10

ofurCSPB

OfurCSP8
OfurCSP7

OfurCsP6

ofurcsp5

ofurCSP2

PxutcSP10

Pxutcsp8a

PxutCSP8

PxutCSP7

PxutCSP6

PxutCsP4

PxutCSP3

Pxutc5P2
PxutcSP1

ExutcsP4a

PxutCSP4a

Pxutcs $4 b$
PxutcSP4c

PxutCSP8b

Pxutcsp11a

PxutCSP11b

PxutCSP12

PxutCSP13

BMorCSP11

BMorCSP9

BMorCSP8

BMorCSP7

BMorCSP6

BMorCSP5

BMorCSP4

BMorCSP3

SexiCSP1
SexicsP2

SexicsP2

SexicSP6

LexiCsP6

LbotCSP21

LbotCSP20

botCSP19

botCSP18

LbotCSP14

LbotCSP13

LbotCSP10

LbotCSP6

LbotCSP5

LbotCSP4

LbotCSP3

LbotCSP2

PxylCSP5

SexicsP $3-2$

exicsP1-2

BMorCSP16

MorCSP15

BMorCSP14

BMorCSP13

BMorCSP11-2

BMorCSP10

BMorCSP9-2

BMorCSP8-2

BMorCSP7-2

BMorCSP6-2

BMorCSP5-2

BMorCSP4-2

MMICSPS-

(1)

HascCS

EhipCsP1

EhipCSP18

EhipCSP15

EhipCSP14

EnipCSP13

Ehipcsp7

EhipCSP6

EhipCSP4

EhipCSP3

EhipCSP2

Consensus

.........................

127
$\ldots \ldots \ldots \ldots \ldots \ldots$

121

- 106

127

114

126

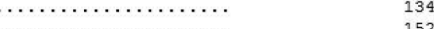

120

123
$\ldots \ldots \ldots \ldots \ldots$

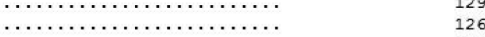

(122

$\begin{array}{ll} & 122 \\ \ldots \ldots \ldots \ldots \ldots \ldots \ldots \ldots \ldots & 125\end{array}$

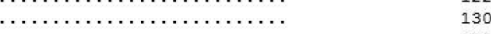

123

129

125

123
122

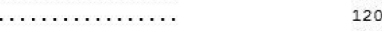

...................... 124

..................... 128

127

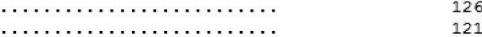

.

125
$\ldots \ldots \ldots \ldots \ldots \ldots \ldots \ldots \ldots \ldots$
122

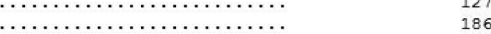

120
129

122

IDQIGYRIIRTTEIVTDILRNTVRAVVG
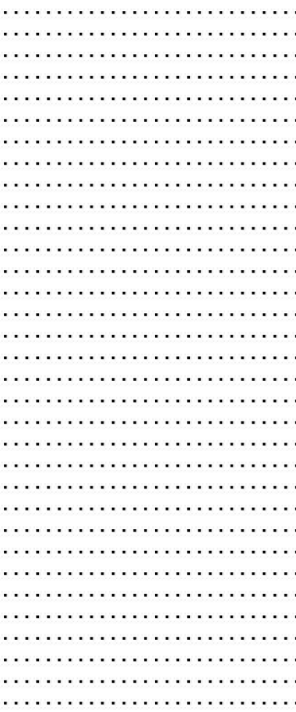

n...,

n.w. 